\title{
NATURALEZA, CLASIFICACIÓN Y EVOLUCIÓN FUTURA DE LAS PARTICIPACIONES PREFERENTES
}

\section{Miguel ÁNgel VillacorTa HeRNÁNDEZ*}

RESUMEN: Este estudio analiza la naturaleza jurídica de las emisiones de participaciones preferentes (PPR), reguladas por primera vez en Espańa en la Ley 19/2003, y que es una figura distinta a las acciones o participaciones sociales preferentes y privilegiadas del TRLSC.

Esta figura es analizada por cinco razones: primero, porque la prensa económica ofrece informaciones equívocas, segundo, porque tienen una regulación detallada que merece ser observada, tercero, porque su legislación guarda muchos aspectos en común con las acciones rescatables, cuarto, porque son las emisiones de híbrido de capital que presentan más éxito en el mercado financiero, y quinto porque es el instrumento elegido por los intermediarios financieros para financiarse en la crisis de 20092011.

La conclusión fundamental es la necesidad de analizar, por separado, la naturaleza de las PPR emitidas de forma directa y las emitidas de forma indirecta.

PALABRAS CLAVE: Participaciones preferentes - capital - híbridos financieros

\section{NATURE, CLASSIFICATION AND FUTURE EVOLUTION OF THE PREFERRED SHARES}

ABSTRACT: This article analyzes the juridical nature of the issuing of preferred shares, regulated for the first time in Spain under Law 19/2003, and that is a different figure than those stocks or preferred social shares and privileged of the Adapted Text of the Capital Societies' Law. This figure is analyzed under five reasons: first, because the economic press offers ambiguous information; second, because they have a detailed regulation that deserves a closer observation; third, because its legislation holds several common aspects with the callable stocks; fourth, because

\footnotetext{
* Profesor Universidad Complutense de Madrid. Doctor en Derecho Mercantil, Doctor en Ciencias Económicas y Empresariales. Correo Electrónico: mianvi@emp.ucm.es Fecha de recepción: 21 de noviembre de 2011.

Fecha de aceptación: 19 de marzo de 2012.
} 
they are the most successful issuing of hybrid capital in the financial market; and fifth, because it was the chosen instrument by the brokers to receive financing during the 2009-2011 crisis. The main conclusion is the need to separately analyze the nature of the preferred shares issued directly and those issued indirectly.

KEY WORDS: Preferred shares - Capital - financing hybrids

\section{1) CONCEPTUALIZACión}

Este estudio analiza la naturaleza jurídica de las emisiones de participaciones preferentes (PPR), reguladas por primera vez en España en la Ley 19/2003, y que es una figura distinta a las acciones o participaciones sociales preferentes y privilegiadas del TRLSC ${ }^{1}$. Para designarlo se ha utilizado una terminología muy diversa ${ }^{2}$ : "emisiones preferentes", "acciones preferentes en el sistema angloamericano" o, la preferida en este artículo, "participaciones preferentes (PPR)"3.

Esta figura ${ }^{4}$ es analizada por cinco razones: primero, porque la prensa económica ofrece informaciones equívocas ${ }^{5}$, segundo, porque tienen una regulación detallada que merece ser observada, tercero, porque su legislación guarda muchos aspectos en común con las clases de acciones ${ }^{6}$,

1 La nomenclatura de participaciones preferentes tiene su origen en la traducción a la lengua castellana del concepto anglosajón "preferencelpreferred shares", pero omitiendo intencionadamente el concepto "acción". Para designar al instrumento financiero desconocido hasta entonces, el legislador intenta llamar la atención del inversor doméstico sobre el riesgo de confusión con los productos financieros de renta variable a los que estaban habituados.

2 SCHERK, W. (2003) "Emisiones preferentes: a medio camino entre las acciones y las obligaciones", Bolsa de Madrid, marzo, 68-69, p. 68.

3 La nomenclatura y acrónimo propuesto, "participaciones preferentes" y PPR, son los elegidos por el regulador del mercado bursátil espańol: la CNMV. CNMV: Participaciones preferentes (PPR), Oficina de Atención al Inversor CNMV, Madrid, 2008, p. 1.

4 El estudio de las PPR debe tener, indefectiblemente, como punto de partida, dos trabajos que analizan con detalle y minuciosidad los diversos aspectos de la figura. Fernández DeL Pozo, L. (2005) Las participaciones preferentes: un hibrido supletorio del capital social. Madrid: Thompson Civitas; "Gobierno corporativo e híbridos financieros". FernándeZ DEL Pozo, L. (2005) "Derechos políticos en cabeza de no socios. El caso de las participaciones preferentes", en AA.VV Derecho de Sociedades Anónimas cotizadas, vol. I, Revista de Derecho de Sociedades, Thompson-Aranzadi, pp. 571-615.

5 Las dudas sobre la terminología son muy frecuentes en la prensa económica. Martínez denomina a su artículo "Lo que su banco no le dice al ofrecerle acciones preferentes", para comentar la actualidad de las PPR. Martínez, M.: Lo que su banco no le dice al ofrecerle acciones preferentes, Expansión, 17 de mayo de 2009.

6 La regulación de las PPR guarda muchos aspectos en común con las clases de acciones, sobre todo con las acciones rescatables. La similitud entre acciones rescatables y PPR es mostrada por García de EnTerría, J. (1999) "Las acciones rescatables", La Ley, no 4847, p. 2. Conllado Lantero, F. (2002) "La emisión de acciones preferentes por sociedades bancarias españolas", en Libro Homenaje al Profesor Fernando Sánchez Calero, vol. IV, Madrid: 
cuarto, porque son las emisiones de híbrido de capital que presentan más éxito en el mercado financiero ${ }^{7}$, y quinto porque es el instrumento elegido por los intermediarios financieros para financiarse en la crisis de 2009$2011^{8}$.

Para buscar una conceptualización adecuada, es necesario observar la dimensión otorgada por la doctrina, el organismo rector de las Bolsas de valores espańolas (CNMV) y los emisores de instrumentos financieros.

Las definiciones doctrinales de las PPR son imprecisas: "son instrumentos utilizados por entidades financieras para la captación de recursos a largo plazo" 9 . Esta definición es mejorable en dos aspectos. Primeramente, porque no están emitidos exclusivamente por entidades financieras ${ }^{10}$. Además, es necesario una mejor especificación, porque la captación de recursos a largo plazo también puede obtenerse por medio de empréstitos, deudas y otro tipo de emisiones.

La CNMV ofrece una caracterización en tres sentidos: realizar una comparación en virtud de la similitud con otros instrumentos financieros,

n/d, pp. 4014 y ss. Yanes YANes, P. (2004) Las acciones rescatables en la sociedad cotizada. Cizur Menor (Navarra): Thomson-Aranzadi, pp. 82 y ss. A todo esto hay que ańadir que algunas PPR se parecen, aún más si cabe, a algunas acciones rescatables con características muy determinadas. Las acciones rescatables a opción de la sociedad emisora se parecen a las PPR en que ambas conceden al emisor la posibilidad de rescate trascurrido un plazo (tres ańos para rescatables y cinco ańos para PPR).

7 Dentro de los híbridos financieros de capital, destacan, desde el final del siglo XX, por su importancia en número de emisiones y volumen de negociación, la figura de las PPR. Pero incluso, en los últimos ańos su frecuencia es mayor, tanto que las PPR se han convertido en el producto financiero de moda en el ańo 2009. En los primeros seis meses de 2009 se han emitido en Espańa más de 12.000 millones de euros en este tipo de activo. Durante el año 1999, Caja Madrid lanzó una emisión por un importe de 3.000 millones de euros; la Caixa 1.500 millones; BBVA 1.000 millones, SCH 2.500 millones, Banesto 500 millones, Banco Sabadell 500 millones, Caja Castilla-La Mancha 1.300 millones, Banco Pastor 250 millones y Banco Popular 425 millones. García Vega, M.A. (2009) "El riesgo de invertir en las 'preferentes", http://www.dossierempresarial.com/leernoticia.asp?id=3557.

8 «La banca se está reforzando en recursos propios. La salida a bolsa está complicada y, por eso, recurren a la emisión de preferentes». "(...) Otros recursos para captar financiación, como las ampliaciones de capital, son más caras para las entidades y, además, con ellas se traslada la imagen de que el banco o caja tiene problemas de solvencia" (...) "Este aluvión de participaciones preferentes responde pues al afán de bancos y cajas de ahorro de captar liquidez en esta época de crisis económica y reforzar con ello sus ratios de solvencia (Tier 1) frente a la oleada de la morosidad". García Vega, M.A (2009). Por otro lado "(...) el Banco Santander ha echado mano de ellas para compensar a sus clientes afectados por el escándalo Madoff". Fernández, D.: "El jaleo de las preferentes". En Dinero \& inversiones, 12 de abril de 2009.

9 Alonso Conzález, P (2001) "Las participaciones preferentes en España", Actualidad Financiera, julio, no $7,19-31$, p. 19.

10 Las PPR no solo son emitidas por los intermediarios financieros, aunque son los casos más frecuentes, sino que son utilizadas también por otro tipo de empresas. Entre los emisores de PPR que no son intermediarios financieros destacan las eléctricas, como Endesa, pero también las Corporaciones locales, como los ayuntamientos de Madrid y Barcelona, el cabildo de Tenerife o la diputación foral de Guipúzcoa, y organismos públicos como la Feria de Valencia o RTVE. 
analizar directamente sus características principales y, por último, establecer una definición expresa. Por un lado, establece que "son similares a la deuda subordinada por su orden de prelación en el crédito. Sin embargo, para el emisor es un valor representativo de su capital social desde el punto de vista contable (lo que lo aproxima al concepto de renta variable), si bien otorgan a sus titulares unos derechos diferentes a los de las acciones ordinarias: no tienen derechos políticos ni derecho de suscripción preferente" 11 . En segundo lugar, establece sus características fundamentales ${ }^{12}$ : (a) conceden a sus titulares una remuneración predeterminada (fija o variable), no acumulativa, condicionada a la obtención de suficientes beneficios distribuibles por parte de la sociedad garante (es decir, de la entidad espańola) o del grupo financiero al que pertenece; (b) se sitúan en orden de la prelación de créditos por delante de las acciones ordinarias (y de las cuotas participativas en el caso de las cajas de ahorros) y por detrás de todos los acreedores comunes y subordinados; (c) las PPR son perpetuas, aunque el emisor podrá acordar la amortización una vez transcurridos al menos cinco años desde su desembolso, previa autorización del garante y del Banco de Espańa. Por último, la CNMV define las PPR de forma concreta: "Son valores emitidos por una sociedad que no confieren participación en su capital ni derecho de voto. Tienen carácter perpetuo y su rentabilidad, generalmente de carácter variable, no está garantizado. Pueden generar rentabilidad, pero también pérdidas en el capital invertido. El emisor suele reservarse el derecho a amortizarlas a partir de los cinco ańos, previa autorización del Banco de España" 13 .

También son destacables las definiciones de PPR ofrecidas por los emisores. Como ejemplo mostramos la realizada por Bankia ${ }^{14}$ : "Son valores que normalmente se emiten a través de una sociedad extranjera, y que son filial de una entidad espańola que actúa como garante. Presentan diferencias respecto de la Renta Fija y de la Renta Variable. Por su estructura son similares a la Deuda Subordinada y a efectos contables se consideran valores representativos del capital social del emisor, que otorgan a sus titulares unos derechos diferentes a los de las acciones ordinarias, pues carecen de derechos políticos y del derecho de suscripción preferente" 15.

11 CNMV (2002) Los productos de renta fija. Madrid: CNMV, p. 14.

12 CNMV (2002) 14.

13 CNMV (2008) Participaciones preferentes (PPR), Oficina de Atención al Inversor. Madrid: CNMV, p. 1.

14 Bankia (n/d) "Valores: renta fija", Página web corporativa, http://www.bankia d.es/CajaMa$\mathrm{drid} /$ Home/cruce/0,0,199_997818*3839,00.html [consulta realizada el 10/6/2010]

15 Junto a la definición de la figura, Bankia resume sus principales características (que son coincidentes con lo establecido en la CNMV). La primera es que "conceden a los titulares una remuneración predeterminada (fija o variable), no acumulativa periódica, condicionada a la obtención de suficientes beneficios distribuibles por parte de la sociedad garante. La segunda es que "se sitúan en el orden de la prelación de créditos por delante de las acciones 
Las nociones anteriores no son satisfactorias por no tener carácter definitorio, por lo que este artículo ofrece una definición ${ }^{16}$, basándose en la idea de que las PPR son una agrupación de instrumentos financieros incluidos dentro de los híbridos de capital ${ }^{17}$. La definición propuesta es que las PPR son instrumentos financieros híbridos de capital sin la calificación jurídica de acciones o participaciones sociales ${ }^{18}$. Esta definición es concordante con la concepción generalizada del mercado financiero, donde se considera como PPR a las emisiones similares a las acciones y participaciones sociales, pero sin la calificación jurídica de éstas.

La conceptualización de las PPR como híbridos de capital sin la calificación jurídica de acciones o participaciones sociales se establece a través de una clasificación de los híbridos de capital. Los "híbridos financieros"19 se pueden dividir en "híbridos financieros de capital" 20 e "híbridos financieros de deuda"21. Los "híbridos financieros de capital" se dividen a su vez en "híbridos financieros de capital sin calificación jurídica de acciones o participaciones sociales" (donde se encuentran las PPR) e "híbridos financieros de capital con calificación jurídica de acciones o participaciones sociales". Por su parte, los "híbridos financieros de deuda" se clasifican en "híbridos financieros de deuda sin calificación jurídica de

ordinarias", por último, "las participaciones preferentes son perpetuas, aunque el emisor podrá acordar la amortización una vez transcurridos al menos cinco ańos desde su desembolso".

16 Nuestra definición es solamente mercantil, sin incidir en los aspectos contables, al contrario que equivocadamente mezclan los emisores de PPR.

17 La consideración de las PPR como híbridos de capital es compartido por la doctrina. Mourgues, N. (1996) Capitaux propres et quasi fonds propres. Paris: Économie. Engel, E.; Erickson, M.; Maydew, E. (1999) "Debt-equity hybrid securities", Journal of Accounting Research, no 2, pp. 249-274. Lamandini, M.(2001) Struttura finanziaria e gobernó nelle societa di capital. Bologna: Il Mulino, pp. 23 y ss. Pisano Massamormile, A.: (2003)"Azioni ed altri strumenti finanziari partecipaviti”, Rivista delle Societá, pp. 1268-1315.

18 También puede existir confusión terminológica entre las participaciones preferentes (PPR) y las participaciones sociales. Las PPR son híbridos de capital sin la calificación jurídica de acciones o participaciones sociales, mientras que las participaciones sociales son cada una de las partes en las que está dividido el capital en las sociedades de responsabilidad limitada.

19 Los hybrid securities tienen algunas características de acciones y otras características de obligaciones. Henn, H. G.; Alexander, J.R. (1986) Laws of Corporation. Saint Paul, Minnesota: West Publishing Co., p. 409 y ss. Hamilton, Robert W. (1996) The Law of Corporation. St. Paul, Minnesota: West Publishing Co., p. 211 y ss. Klein, W.A.; Coffee, J.C.J. (2000) Business organization and finance, $7^{\mathrm{a}}$ ed. New York: Westbury, p. 225.

20 Los híbridos de capital son los híbridos financieros constituidos por una emisión de deudas utilizadas en función de capital. La denominación propuesta "híbridos financieros de capital" tiene su correspondencia con otras utilizadas por la doctrina: quasi-equity, funktionelles Eigenkapital o mezanine debt. Mourgues (1996). Engel/Erickson/Maydew (i999) 249274. Lamandini (200i) 23 y ss. Pisano Massamormile (2003) 1268-1315.

21 Dentro de la categoría híbridos de deuda se agrupan todos los híbridos financieros compuestos por acciones o participaciones sociales que son utilizadas como deudas. La denominación propuesta "híbridos financieros de deuda" se corresponde con otras utilizadas por la doctrina: quasi- debt o mezanine equity. Mourgues (1996). Engel/Erickson/Maydew (i999) 249-274. Lamandini (200i) 23 y ss. Pisano Massamormile (2003) 1268-1315. 
acciones o participaciones sociales" e "híbridos financieros de deuda con calificación jurídica de acciones o participaciones sociales".

Los híbridos de capital eran originariamente deudas, pero posteriormente, al ser utilizados como si fuesen capital, se convierten en un instrumento de carácter económico mixto pero de difícil calificación jurídica. Dependiendo de su calificación jurídica existen dos agrupaciones: los híbridos financieros de capital con la calificación jurídica de acciones o participaciones sociales y los híbridos financieros de capital sin la calificación jurídica de acciones o participaciones sociales. De la misma forma, los híbridos de deuda eran originariamente acciones o participaciones sociales, pero que posteriormente, al ser utilizados como si fuesen deuda, pasan a ser un instrumento de carácter económico mixto pero de difícil calificación jurídica. Dependiendo de su calificación jurídica existen dos agrupaciones: los híbridos financieros de deuda con la calificación jurídica de acciones o participaciones sociales y los híbridos financieros de deuda sin la calificación jurídica de acciones o participaciones sociales.

Dentro de las PPR también es posible realizar otra clasificación, la que diferencia entre participaciones emitidas de forma directa (emitidas directamente por la propia empresa) y las emitidas de forma indirecta (emitidas por medio de filiales en el extranjero). Las "PPR emitidas de forma indirecta" son instrumentos financieros híbridos de capital sin la calificación jurídica de acciones instrumentalizados por medio de filiales que operan en mercados distintos a los inversores a los que van dirigidos. Las "PPR emitidas de forma directa" son instrumentos financieros híbridos de capital sin la calificación jurídica de acciones emitidas por empresas en el mismo mercado de los inversores a los que va dirigidos.

Las PPR cumplen tres características: son instrumentos financieros, no tienen la calificación jurídica de acciones ni de participaciones sociales y son híbridos de capital. Por su parte, las PPR emitidas de forma indirecta cumplen cuatro características: son instrumentos financieros, no tienen la calificación jurídica de acciones ni participaciones sociales, son híbridos de capital, pero además, utilizan filiales que operan en diferente mercado al de la empresa matriz.

La génesis de las PPR está en las emisiones realizadas de forma indirecta realizadas por empresas estadounidenses a través de empresas instrumentales. Por medio de estas empresas pantalla (sociedades instrumentales, sociedades vehículos, entidad interpuesta, conduits, filial instrumental, SPV, Special Purpose Vehicle) se convierte la deuda en capital.

El mecanismo de emisión de forma indirecta es el siguiente. La sociedad instrumental emite PPR. Una vez suscritos los valores, la empresa pantalla pone a disposición de la matriz los recursos financieros obtenidos con la emisión, lo que se formalizaba jurídicamente como una deuda a largo plazo de naturaleza subordinada (junior-subordinated deferrable-in- 
terest debentures) ${ }^{22}$ entre la matriz y la empresa instrumental. Los intereses de este préstamo reproducen la cadencia de los pagos de los instrumentos participativos, de manera que se permite de este modo a la empresa pantalla el pago de los dividendos devengados por las participaciones emitidas a su vencimiento ${ }^{23}$.

Esta complicada construcción tiene su justificación en la búsqueda de la mejor calificación posible del instrumento. Desde la perspectiva fis$\mathrm{cal}^{24}$, los intereses de la deuda contraída con la empresa pantalla representan un gasto financiero de la matriz a efectos fiscales, mientras que desde la perspectiva regulatoria ${ }^{25}$, las emisiones se consideran recursos propios básicos (Tier 1 Capital) ${ }^{26}$.

Sobre la naturaleza de las PPR, existen muchas dudas sobre si son pasivo exigible o pasivo no exigible ${ }^{27}$. El art. 7 de la Ley 13/1985, de 25 de mayo, de Coeficientes de Inversión, Recursos Propios y Obligaciones de Información de los Intermediarios Financieros (Ley 13/1985) establece que las PPR son recursos propios. Algunos autores aportan argumentos diversos para afirmar que integran el pasivo exigible, mientras que otros los ofrecen para aseverar que son pasivo no exigible ${ }^{28}$. Por un lado, se es-

22 Bajas, Mukesh; Mazumdar, Sumon, C; Sarin, Atulya (2002) "The cost of issuing preferred stock", Journal of Financial Research, 25 (4), pp. 577-592. CARY; Collins; Wansley (2003) "The impact of trust preferred issuance of bank default risk and cash-flow: evidence from the debt and equity markets", The Financial Review, may, vol. 38, no 2, pp. 235 y ss. Harris, A. J. (2004) "Trust preferred securities still eligible capital treatment; new rules are a compromise", Banking law journal, vol. 121, no 8, p. 688.

23 Khana, A; Mc Connel, J.J. (1998) "MIPS, QUIPS and TOPRS: old wine in new bottles", Journal of Applied Corporate Finance, no 1, p. 40. Sinkey, J.F.J. (2003) "Bank capital structure, regulatory capital, and securities inonovations", Journal of Money, Credit \& Banking, no 3, 301-335, p. 301. Fernández del Pozo, L. (2005) Las participaciones preferentes: un hibrido supletorio del capital social. Madrid: Thompson Civitas, p. 14.

24 La perspectiva fiscal puede observarse en Heskins, M. (1995) "Can the IRS maintain the debt-equity distinction in the face of structures notes?”, Harvard Journal of Legislation, 32, pp. 524 y ss.

25 La perspectiva regulatoria puede observarse en Frischmann, P. J.; Kimmel, P.D.; Warfield, T.D. (1999) "Innovation in preferred stock: current developments and implications for Financial Reportings", Accounting Horizons, september, pp. 201-218.

26 La utilización masiva de las PPR se produce a partir del 21 de octubre de 1996, cuando la Reserva Federal estadounidense reconoció a las holdings bancarias (bank holding companies) la posibilidad de inscribir el capital suministrado en recursos propios básicos.

27 Las dudas sobre su naturaleza se derivan, fundamentalmente, porque las PPR "combinan un riesgo intermedio entre el de renta fija y el de renta variable". CNMV (1999) Informe Anual sobre Mercados de Valores. Madrid: CNMV.

28 Las PPR son distintas de las acciones, de los instrumentos de deuda y de las cuotas participativas de las cajas de ahorro. En este sentido, la doctrina afirma que la diferenciación tipológica entre PPR y acciones "es muy oscura". Fernández del Pozo, L.: "Gobierno corporativo e híbridos financieros. Derechos políticos en cabeza de no socios. El caso de las participaciones preferentes", en AA.VV Derecho de Sociedades Anónimas cotizadas, vol. I, Revista de Derecho de Sociedades, Thompson-Aranzadi, 2005, pp. 600-601. El autor continúa afirmando que las PPR "no son acciones ni obligaciones, sino que realmente son participaciones prefe- 
tablece un argumento por el que las PPR no son acciones ni participaciones sociales: "La base de cálculo de este denominado dividendo es el valor nominal de las PPR y no el beneficio repartible; siendo el porcentaje aplicable a dicha base de cálculo una tasa de interés y no la expresión aritmética de la parte alícuota del capital social desembolsado de cada socio" 29 . En nuestra opinión, éste no puede ser un criterio para diferenciar si son acciones o participaciones sociales, porque las acciones o participaciones sociales privilegiadas, que son claramente clases de acciones o participaciones sociales, pueden estar configuradas de forma que tengan una remuneración predeterminada ${ }^{30}$. Por otro lado, otra autora establece que las PPR “(...) son recursos propios pero no integran el capital social”31. Este argumento tampoco puede ser utilizado con el PGC 2007, donde existen diversas acciones (algunas acciones rescatables, sin voto y preferentes) que no forman parte del capital social ${ }^{32}$. Por último, se ha afirmado que todas las PPR son pasivo no exigible, al afirmar que “(...) las participaciones preferentes integran el capital social de una sociedad anónima" ${ }^{33}$. En nuestra opinión, esto no es cierto porque es imposible generalizar la naturaleza de las PPR; es imprescindible diferenciar entre emisiones directas e indirectas. Por tanto, la naturaleza de las PPR depende de si son directas e indirectas, y en función de ello, se propondrá una calificación de cada una de ellas.

rentes; nuestra Ley ha tipificado un nuevo híbrido financiero como tertium genus entre los dos modelos paradigmáticos de financiación permanente". CNMV (1999) 604.

YANES YANes (2004) p. 88.

El legislador huye del término técnico "dividendo" para referirse a la remuneración predeterminada del instrumento financiero PPR. Por otro lado, la Ley requiere su cotización en "mercados secundarios organizados", y no necesariamente en la bolsa, como ocurría con las acciones cotizadas espańolas. Además, a los inversores no se les hace referencia como accionistas, sino como "titulares".

Chamorro Domínguez, M.C. (2007) Las acciones rescatables de la sociedad anónima cotizada. Madrid: La Ley, pp. 134 y ss.

El preámbulo de la Ley 16/2007, de 4 de julio, expresa el cambio en la contabilización de las clases de acciones, incidiendo en que algunas clases de acciones, y no todas serán pasivos financieros: "En concreto, por lo que se refiere a determinados elementos de balance debe resaltarse que la convergencia del Derecho Mercantil Contable interno (Código de Comercio y sus disposiciones de desarrollo) con las normas internacionales, originará un cambio fundamental en la calificación económico-contable de algunos instrumentos financieros utilizados por las empresas espańolas para obtener los recursos necesarios para el desempeńo de su actividad. En particular, determinadas acciones rescatables y acciones o participaciones sin voto. De acuerdo con estas definiciones, puede comprobarse que el nuevo modelo contable exigirá una delimitación más precisa de las partidas incluidas en el patrimonio neto, a partir de la definición de los pasivos. Este análisis deberá atender no solo a la forma jurídica, sino especialmente a la realidad económica de las operaciones, habiéndose incluido este aspecto de manera explícita en el art. 34, apartado 2, del Código de Comercio. Es decir, se exige en última instancia una calificación de los hechos económicos atendiendo a su fondo, tanto jurídico como propiamente económico, al margen de los instrumentos que se utilicen para su formalización".

Chamorro Domínguez (2007) 135. 
Las PPR emitidas de forma indirecta serán analizadas en el tercer apartado, mientras que las PPR emitidas de forma directa serán analizadas en el cuarto apartado.

\section{2) HÍBRIDOS FINANCIEROS DE CAPITAL}

La innovación financiera es el proceso de elaboración y puesta a disposición del cliente de fórmulas de financiación, inversión y de cobertura de riesgos ${ }^{34}$. Los productos resultantes de la innovación financiera nacen de los principios del Derecho internacional de los que se deriva la autonomía de la voluntad y la libre creación de valores.

De la innovación financiera se han obtenido un elevado número de productos financieros: se han generado los denominados "Nuevos Instrumentos Financieros", en especial los "Instrumentos Derivados", se han estructurado operaciones sobre instrumentos financieros dando lugar a "Instrumentos Sintéticos", y lo más importante, se han diseńado "Instrumentos Financieros Híbridos o Compuestos" con características de acciones y obligaciones a la vez, tomando como base uno de ellos ${ }^{35}$.

De entre todos los medios de innovación financiera, son especialmente relevantes los activos financieros generados en una posición financiera intermedia entre deuda y acción, denominados "híbridos"36 (bybrid securities, hybrid finanzierungsinstrumente, valeurs mobilières hybrides, strumenti finanziari, ibridi/partecipativi). El concepto híbrido financiero agrupa a los instrumentos financieros generados con una posición financiera intermedia entre deuda y acción. El mercado financiero crea unos

La innovación financiera es un proceso integrado por dos subprocesos: la ingeniería financiera y el marketing financiero. El proceso de ingeniería financiera consiste en la construcción y elaboración de productos financieros en los que se materialicen las innovaciones financieras, desarrollando una gran variedad de nuevas fórmulas de financiación, inversión y de cobertura de riesgos. Por su parte, el marketing financiero es el proceso de ofrecer a los clientes el conjunto de innovaciones financieras.

35 Además de las emisiones que estamos aquí analizando, en la actualidad existe una tendencia a diseńar y emitir otros instrumentos atípicos, algunos de los cuales se han regulado para incrementar su transparencia, caso de los futuros, opciones y swaps, frente a otros que no han sido legislados, entre los que se encuentran los productos estructurados, los Over The Counter (OTC) o extrabursátiles. Tal es el número de instrumentos diseńados por las empresas, que pueden considerarse generados por la innovación financiera, que fue preciso elaborar una norma ISO, de ámbito internacional, que facilitase una uniformidad terminología al respecto, para así posibilitar la necesaria transparencia y procesamiento electrónico. La ISO10962 "Clasification of Financial Instruments", publicada en 1997, permite catalogar los instrumentos financieros a partir de la atribución de un código alfabético formado por seis caracteres. A esta norma están adheridos un gran número de países, entre ellos España.

36 El concepto de híbrido financiero es utilizado de forma masiva en la literatura especializada, aunque no todavía en los textos de Derecho positivo. Mourgues (I996) 15-150. EngeL/ Erickson/Maydew (1999) 249-274. Lamandini (2001) 75. Pisano Massamormile (2003) 1268-1315. NELKEN, I. (2000) Handbook of hybrid instruments: convertible bonds, preferred shares, ELKS, DECS and other mandatory convertible notes. John Wiley \& Sons. 
instrumentos con rasgos de deuda y de participación en fondos propios para intentar aprovechar las ventajas de ambas categorías ${ }^{37}$.

El mercado financiero muestra una clara tendencia al acercamiento entre la emisión de deuda y la participación en fondos propios, sin duda para aprovechar las ventajas de la otra categoría, intentando ser más atractiva para la posible elección como inversión. Esa permeabilidad opera en la mayoría de los niveles de distinción, permitiendo encontrar una aproximación en las características de retribución y duración del derecho, produciendo un debilitamiento de la frontera que separa los tradicionales conceptos de acción y deuda. Como hemos visto, no es la única forma de innovación financiera, pero gran parte de los productos que origina pueden englobarse dentro de una mezcla de las dos figuras clásicas de inversión a largo plazo.

Los valores mobiliarios, como instrumentos contractuales, han sido objeto de regulación por los ordenamientos mercantiles continentales europeos (alemán, francés, español e italiano, principalmente), diferenciando entre acciones y obligaciones, siendo infrecuente que se optará por emitir valores atípicos derivados de la innovación financiera. Frente a tal proceder, el modelo anglosajón (Estados Unidos y Reino Unido principalmente), basado en la costumbre y en la primacía de los acuerdos entre las partes, posibilitó la emisión de una gran cantidad de instrumentos. La globalización ha propiciado la permeabilidad entre ambos modelos jurídicos, y de ella ha surgido la necesidad de armonizar los procedimientos de emisión de instrumentos financieros, eliminando las concepciones de índole exhaustiva y excluyente, dando cabida a la libertad de pactar la emisión de los instrumentos entre los intervinientes de acuerdo a sus necesidades y demandas.

Las finalidades para generar un híbrido son las siguientes:

a) Conjugar los aspectos ventajosos de las acciones y de la deuda para resultar más atractivos en el mercado de capitales, ofreciendo a los inversores potenciales, conjuntamente, seguridad y rentabilidad.

b) Atraer los accionistas y acreedores hacia su producto. Los accionistas realizan su inversión con la esperanza de recibir dividendos, los beneficios de las ampliaciones de capital y el aumento de cotización de las acciones. Por el contrario, los prestamistas esperan tanto el pago de un interés por la cesión temporal de los fondos, como la devolución del principal en los plazos establecidos en el contrato.

c) Conseguir perfiles de rendimiento-riesgo iguales a los instrumentos

37 Todo esto ha permitido afirmar que la financiación con híbridos financieros "tiene su origen en la diversificación financiera". Howells, P.; BaIN, K. (2002) The economics of money, banking and finance, $2^{\mathrm{a}}$ ed., Prentice Hall, p. 487. 
tradicionales pero con alguna ventaja comparativa: menores costes de transacción, mayor liquidez o mayor apalancamiento.

d) Mejorar la rentabilidad a cambio de perder derechos políticos o ganar en liquidez y disminuir el riesgo.

e) Intentar acercarse a la posición óptima de confeccionar un título con las características económicas de fondos propios pero con la calificación fiscal de deuda ${ }^{38}$.

Las categorías más frecuentes de híbridos son cuatro:

a) Potestad de transformación. El primer caso es el de un valor financiero potencialmente convertible en otro. Los ejemplos más representativos de esta categoría son las obligaciones convertibles en acciones ${ }^{39}$ y los warrants, entendidos como derechos autónomos para suscribir acciones de la misma sociedad o de otra. Históricamente, los primeros híbridos tuvieron el origen en la emisión de empréstitos convertibles ${ }^{40}$. En el mercado estadounidense actual, todavía perviven un gran número de híbridos financieros con potestad de transformación: bonos que ofrecen una conversión en acciones a voluntad del emisor (call debt), a un precio establecido (call price) o con un sobrepago o premio (call premiun), bonos que son canjeables por acciones ya existentes en circulación, sin ampliación (excheangable bonds), bonos con derecho a adquirir, a un precio cierto, acciones de nueva emisión (equity warrants) y bonos con opción doble, o para canjearlos por acciones o para revenderlos nuevamente al emisor (convertible puttable bond).

b) Intercambio de derechos. Existe la posibilidad de emitir productos financieros en los que los titulares reciben un derecho adicional a cambio de no poder ejercer algún otro al que normalmente podrían beneficiarse. Las emisiones más utilizadas son las acciones que reciben un derecho adicional en la remuneración a cambio de la limitación en la intervención en la gestión empresarial (por ejemplo, algunas, no todas, acciones sin voto).

c) Híbridos de duración. Esta categoría se produce al alargar los plazos de amortización de la deuda hasta convertirse en indefinidos (obligaciones perpetuas ${ }^{41}$ ) y, en sentido contrario, permitir la amortización

La emisión de acciones es más gravosa fiscalmente que la emisión de otros valores como la deuda y los empréstitos, ya que los dividendos están más gravados que los intereses. En ciertas aspectos las PPR consiguen alcanzar esta última finalidad.

39 Aunque el emisor de ambas figuras no tiene obligación de pagar los cupones, en caso de no obtener beneficios, las obligaciones convertibles tienen mayor liquidez que las PPR.

40 La primera emisión de híbridos financieros fue realizada, en 1850, por la Erie Railroad estadounidense, y consistió en una convertible bonds que anexaba una opción que otorgaba el derecho a canjearlos por acciones al inversor. Schwartz, R.J.; Clifford W.S.J. (1993) Advanced Strategies in Financial Risk Management. New York: New York Institute of Finance.

41 Dentro del concepto amplio de obligaciones perpetuas, encontramos las irredeemable annui- 
de los recursos propios en un momento anterior a la extinción de la sociedad (acciones rescatables). Las obligaciones perpetuas son los integrantes de un empréstito que carece de un plazo establecido de amortización. En su carácter puro no han sido utilizadas masivamente porque la incertidumbre, la inflación y la volatilidad de los tipos de interés las convierte en una inversión un tanto peligrosa; sin embargo, sí pueden ser interesantes en los casos que sean actualizables o revisables, o aún mejor, que concedan una opción de amortización para ambas partes. Por su parte, las acciones rescatables son utilizadas en muchos países desde hace tiempo, aunque en Espańa no ha existido regulación hasta la LRLMV de 1998.

d) Híbridos de retribución. Por un lado, existen múltiples fórmulas de interesar al prestamista en la gestión, fundamentalmente, vinculando su retribución a la marcha próspera o adversa del prestatario (admisión de riesgo por parte de ciertos acreedores como en las obligaciones participativas). Por el otro, es posible incluir medios para garantizar un privilegio retributivo mínimo del socio (parcial exoneración del riesgo empresarial como en los dividendos preferentes).

En conclusión, el concepto híbrido financiero agrupa a los instrumentos financieros generados con una posición financiera intermedia entre deuda y acción. Los híbridos financieros se dividen en híbridos de capital e híbridos de deudas. Los híbridos de capital son los híbridos financieros constituidos por una emisión de deudas utilizadas en función de capital; por su parte, la categoría híbridos de deuda recoge todos los híbridos financieros compuestos por acciones o participaciones sociales que son utilizadas como deudas. Los híbridos de capital eran originariamente deudas, pero posteriormente, al ser utilizados como si fuesen capital, se convierten en un instrumento de carácter económico mixto pero de difícil calificación jurídica. Dependiendo de su calificación jurídica existen dos agrupaciones: los híbridos financieros de capital con la calificación jurídica de acciones o participaciones sociales y los híbridos financieros de capital sin la calificación jurídica de acciones o participaciones sociales. De la misma forma, los híbridos de deuda eran originariamente acciones o participaciones sociales, pero que posteriormente, al ser utilizados como si fuesen deuda, pasan a ser un instrumento de carácter económico mixto pero de difícil calificación jurídica.

Este trabajo se limita a estudiar la regulación de las PPR emitidas por empresas españolas, por ser la figura más representativa de los híbridos

tes, obligaciones perpetuas cuya restitución está prevista en el momento de la liquidación de la sociedad y las trust preferred securities, títulos de débito de larguísima duración, las cuales atribuyen a un derecho al reembolso postergado respecto a todos los otros débitos de la sociedad emisora. 
de capital, entendidos como híbridos financieros constituidos por deudas utilizadas como capital.

Un análisis detallado de las PPR supone diferenciar entre las emitidas de forma indirecta por sociedades españolas en paraísos fiscales (apartado 3) y las PPR emitidas de forma directa, que en Espańa fueron regulados por la Ley 19/2003 (apartado 4). Esta clasificación tiene la máxima importancia porque no es posible establecer la naturaleza jurídica de las PPR sin realizar esta diferenciación.

\section{3) PARTICIPACIONES PREFERENTES EMITIDAS DE FORMA INDIRECTA}

A todas las emisiones de acciones y participaciones sociales emitidas en España, es necesario añadir las emisiones de PPR realizadas por capital español en el extranjero.

Los intermediarios financieros espańoles han mantenido una tendencia alcista a emitir PPR de forma indirecta en otros países ${ }^{42}$, sin duda provocado por las condiciones más ventajosas que ofrecen esos países respecto al nuestro ${ }^{43}$.

Con anterioridad a la regulación española sobre PPR, las sociedades financieras cotizadas españolas realizaban emisiones de preference shares en los mercados internacionales a través de filiales domiciliadas en "territo-

42 Los bancos espańoles mantenían "una tendencia alcista a emitir participaciones preferentes de forma indirecta en el extranjero”. El PAís (1998) Negocios, 13 de diciembre de 1998, http://www.elpais.es/, [consulta realizada el 26 de mayo de 2010].

43 Como ejemplo, se encuentran las emisiones realizadas por BBVA, BSCH, La Caixa, Bankinter, Bancaja, Banco Popular, Cajamurcia, Cajasur y Caja de Ahorros de Huelva y Sevilla, analizadas en el estudio empírico. 
rios de baja tributación" ${ }^{44}$, fundamentalmente las Islas Caimán ${ }^{45}$, buscando recursos de inversores de otros países.

Las PPR son la adaptación a los mercados españoles de la práctica financiera internacional, de inspiración estadounidense, de las acciones preferentes emitidas a través de empresas instrumentales: las MIPS, QUIPS o TOPR.

La emisión se realiza a través de una filial instrumental, que tiene por objeto exclusivo la realización de este tipo de emisiones para financiar la actividad del grupo. La Special Purpose Vehicle se domicilia en un "territorio de baja tributación" para aprovechar las ventajas tributarias que concede. La emisión recibe una certificación de solvencia (rating) muy cualifi-

44 La denominación de estos territorios varía según el organismo que lo regula. El FMI los denomina "centro financiero extraterritorial" (offshore), la OCDE tax haven ("paraíso fiscal" o la mejor traducción "refugio o guarida fiscal”), mientras que en este artículo se propone utilizar "territorios de baja tributación”. El FMI define los centros financieros extraterritoriales como "centros donde el grueso de las transacciones del sector financiero (...), se efectúa con individuos o compañías que no son residentes de los centros, donde las transacciones se inician en otro lugar y donde la mayoría de las instituciones implicadas están controladas por no residentes" (trad.). Fondo Monetario Internacional (2002) Offshore Financial Centers. The Role of the IMF, june 2002, 23. El R.D. 1080/91, de 5 de julio, entiende por paraíso fiscal "(...) al territorio o Estado que se caracteriza por la escasa o nula tributación a que someten a determinada clase de transacciones, ventas o a determinadas personas o entidades que allí encuentran su cobertura y amparo", es decir, carecen de impuestos sobre la renta o el patrimonio o son puramente simbólicos. El concepto de territorio de baja tributación tiene otra dimensión: jurisdicciones que prestan servicios financieros a clientes cuya actividad principal se desarrolla en otra jurisdicción, acogiéndose a la menor o nula tributación y a una mínima regulación normativa y sobre todo no cooperadoras con la comunidad internacional.

45 Aunque las sociedades espańolas hayan elegido preferentemente la opción de emitir sus emisiones en las Islas Caimán, este no es el único "territorio de baja tributación”. Entre los treinta y cinco paraísos fiscales identificados por la OCDE encontramos, además de los del área caribeńa de influencia estadounidense, otros muchos en el área europea, tales como las islas de Man, Jersey o Guernesey, dependencias todas de la Corona Británica; Andorra, Mónaco (estrechamente vinculado con Francia) y Liechtenstein. En el ordenamiento espańol, el R.D. 1080/91, de 5 de julio, fijó cuarenta y ocho países o territorios como paraísos fiscales. Por su parte, la Directiva 29003/48/CE del Consejo, de 3 de junio de 2003, "en materia de fiscalidad de los rendimientos del ahorro en forma de pago de intereses" (Directiva del ahorro) estableció quince territorios sobre los que debía protegerse la Unión Europea ante la fuga de capitales: Suiza, Liechtenstein, Mónaco, Andorra, San Marino y diez territorios dependientes o asociados (Islas Caimán, Jersey, las Antillas holandesas, Montserrat, Aruba, Anguilla, Islas Vírgenes, Guernsey, Isla de Man, las Islas turcas y Caicos). Por su parte, en el ańo 2000, el FMI realizó un estudio de evaluación de 42 centros financieros extraterritoriales cuyas actividades irregulares representan serios riesgos para el sistema financiero global. Fondo Monetario Internacional (2002) Offshore Financial Centers. The Role of the IMF, 23 june 2002. Teniendo en cuenta cualquiera de los listados de regiones, existe una geografía de minúsculos puntos que representan cifras astronómicas en las finanzas internacionales. La gran parte de la inversión en paraísos fiscales tiene como destino las Islas Caimán (42\%) y las Islas Vírgenes (40,6\%), lo que supone que entre las dos se alcanza el 82,6\% de toda la inversión española declarada en paraísos fiscales. Expansión: "Solbes bloquea la fuga de capitales hacia los grandes paraísos fiscales", Diario Expansión, 31 de mayo de 2005, pág. 28. 
cada gracias a que el pago queda garantizado irrevocable y solidariamente por la sociedad dominante espańola.

Los derechos políticos y económicos de cada una de las PPR son similares a los conferidos a las acciones (o participaciones sociales) preferentes, sin voto y rescatables. Entre los derechos patrimoniales destaca la retribución participativa garantizada por la matriz, no acumulativa y condicionada a la solvencia del grupo emisor ${ }^{46}$, y el derecho a percibir el precio de amortización (cuota de liquidación) en caso de disolución ${ }^{47}$. En ambos derechos existe una subordinación al pago preferente de los demás acreedores. Entre los derechos políticos se incluye el nombramiento de una fracción de los administradores de la sociedad dominante y garante de la emisión en caso de insolvencia de éstas o del grupo.

Las PPR emitidas de forma indirecta son híbridos financieros que compiten con el resto de formas de financiación, y lo hacen con éxito, porque tienen ventajas jurídicas, fiscales, administrativas y procedimentales. La emisión consigue tener una calificación jurídica muy favorable. Los emisores de PPR obtienen ventajas fiscales ${ }^{48}$ con la utilización instrumental del paraíso fiscal y tienen la calificación de gasto deducible del rendimiento satisfecho ${ }^{49}$. En el aspecto administrativo de supervisión, el emisor consigue que el importe de la emisión se compute dentro de recursos propios básicos (Tier one). Desde el punto de vista operativo, la deslocalización de la emisión consigue una flexibilización en el procedimiento de emisión, en comparación con los requisitos que regirían si la emisión se hubiese efectuado por un incremento de capital de la dominante o por una sociedad española del grupo.

Las entidades de crédito espańolas han utilizado filiales constituidas según la legislación de un paraíso fiscal, que ejercen de emisores de las PPR. La entidad de crédito actúa como garante solidario e irrevocable de los compromisos asumidos por la sociedad emisora con los titulares de las PPR. La entidad de crédito matriz se compromete a mantener la totalidad de las acciones del emisor mientras que exista saldo vivo de las PPR en

46 Normalmente, "las participaciones preferentes (PPR) tienen una remuneración fija en un primer periodo y variable durante el resto de la vida del producto. La remuneración está condicionada a la obtención de beneficios distribuibles por parte del emisor o de su grupo y no es acumulable". CNMV (2002) Participaciones preferentes (PPR), Oficina de Atención al Inversor. Madrid: CNMV, p. 2.

47 "Las participaciones preferentes (PPR) son valores emitidos por una sociedad que no confieren participación en su capital ni derecho de voto. Tienen carácter perpetuo y su rentabilidad, generalmente de carácter variable, no está garantizado. Pueden generar rentabilidad, pero también pérdidas en el capital invertido". CNMV (2008) 2.

48 La categorización fiscal de las PPR es detallada en Cazorla Prieto, L. M.; Blázquez LiDoy, E. (2007) “Implicaciones fiscales de las participaciones preferentes", Estudios en homenaje al profesor Pérez de Ayala. Madrid: Editorial Dikynson.

49 Esta ventaja es derivada de la deslocalización, situación que no se debe dar en todas las PPR. 
circulación. Por su parte, las PPR otorgan una serie de derechos económicos y políticos a sus titulares.

\section{1.) DERECHO DE LOS INVERSORES}

La principal ventaja económica para los inversores es que les permite disfrutar de un dividendo preferente no acumulable. El dividendo será entregado con cargo a los recursos disponibles del emisor y, si no es posible, directamente por la entidad de crédito garante. El dividendo es pagadero periódicamente y puede ser fijo o variable ${ }^{50}$. La mayoría presenta un tipo de interés anual o trimestral aplicado sobre el nominal, en función de un índice de referencia ${ }^{51}$.

La percepción del dividendo está sujeta a dos limitaciones. La primera es generalizada para los dividendos preferentes de todo tipo de sociedades, ya que es necesario un beneficio distribuible en la entidad de crédito garante. La segunda limitación es derivada de la regulación particular del sector bancario español, acerca de las situaciones de déficit de recursos propios en las entidades de crédito. Si las entidades de crédito presentan un déficit de recursos propios superior al 20\% del mínimo legalmente establecido (8\%), deberán destinar la totalidad de sus beneficios a reservas conforme a la Ley $113 / 1992^{52}$.

El segundo derecho de los titulares de las PPR es el derecho a percibir el precio de amortización. El emisor se reserva el derecho a amortizarlos a partir del quinto ańo. Cuando el emisor decida hacer uso de la facultad de rescate prevista en el folleto informativo, tendrá que abonar el precio de amortización, que incluye el valor de emisión, incrementado en una cantidad igual al dividendo devengado desde la última fecha de pago de dividendos hasta la amortización. Esto permite mantener un derecho de rescate a opción de la empresa condicionado al transcurso de un periodo corto de tiempo, con un precio bajo ${ }^{53}$.

50 En el ańo 2009, la rentabilidad “(...) oscila entre el 6\% y el 8,25\%. Por ejemplo, Caja Madrid da un 7\%; Santander el 7,5\%; la Caixa un 6\%; Caja Castilla La Mancha (entre el 7,25\% y el 7,50\%)". García Vega, M.A.: "El riesgo de invertir en las 'preferentes', op. cit., 2009.

51 "Aunque el inversor debe saber que solo se abonan estas plusvalías, por término medio, los dos o tres primeros ańos, después se establece un tipo de euríbor más un diferencial, que varía según la entidades". García Vega, M.A. (2009). Por ejemplo, la última emisión de preferentes de la Caixa, lanzada en mayo de 2009, fue realizada por un importe de 1.500 millones de euros (antes ya había puesto en el mercado otros 3.000 millones). La rentabilidad (TAE) era del 6\% durante los dos primeros ańos y, a partir del 30 de junio de 2011, la retribución será del euribor a tres meses más un diferencial del 3,5\%.

52 Ley 113/1992 de Recursos Propios y Supervisión en Base Consolidada de las Entidades Financieras (BOE 2/6/1992).

53 Aunque no se consideren en el contrato de emisión como "rescatables", pueden ser consideradas como tales, más aun cuando se observa su concordancia con la legislación espańola sobre las acciones rescatables, ya que es necesario que transcurra un plazo para poder ejercer el derecho de rescate a opción de la empresa. 
El último derecho económico es el derecho a percibir la cuota de liquidación en los casos de disolución y liquidación simultánea del emisor y su garante.

Respecto a los derechos mixtos, las PPR no poseen derecho preferente de suscripción sobre las emisiones futuras.

Los titulares no pueden ejercer sus derechos políticos, pues no tienen ni derecho de asistencia ni de voto en las juntas generales de accionistas, excepto en tres supuestos excepcionales: el impago íntegro de un número determinado de dividendos preferentes consecutivos, la modificación sobrevenida de los derechos otorgados por las PPR, en cuyo caso será necesario recabar el previo acuerdo favorable de sus titulares adoptado con mayoría reforzada, y por último, la disolución y liquidación del emisor, dentro de ciertas condiciones y límites ${ }^{54}$.

\section{2.) INCORPORACIÓN A NUESTRA LEGISLACIÓN Y MERCADO}

La observación del gran número de emisiones de PPR realizadas de forma indirecta por empresas espańolas, permite afirmar que las entidades

54 El análisis de los derechos que poseen los titulares de unas PPR emitidas de forma indirecta son observados por el detalle de los que poseen los emitidos por ENDESA Capital Finance, LLC. En cuanto a su naturaleza jurídica, las PPR forman parte del capital social del emisor, pero otorgan a sus titulares unos derechos que difieren de los correspondientes a las acciones ordinarias.

Las PPR de ENDESA otorgan a sus titulares los siguientes derechos:

(i) Dividendos. Las PPR conceden a sus titulares el derecho a percibir un dividendo variable preferente y no acumulativo, pagadero por trimestres vencidos, cuya distribución está condicionada a la existencia de beneficio distribuible, aunque esta limitación no será aplicable si el garante paga dividendos a los titulares de acciones ordinarias u otros valores de rango inferior a las PPR. Si por razón de lo anterior no se pagaran en todo o en parte dividendos a los titulares de las PPR, el emisor no pagará dividendos a los titulares de sus acciones ordinarias.

(ii) Derechos políticos. Los titulares de PPR carecen de derechos políticos con excepción de tres supuestos: falta de pago íntegro de los dividendos durante cinco períodos de dividendo consecutivos, cualquier modificación o supresión de los derechos otorgados por las PPR y en acuerdos de liquidación o disolución del emisor.

(iii) Derecho de suscripción preferente. Las PPR no otorgan, a sus titulares, derecho de suscripción preferente respecto de eventuales emisiones futuras de Preferred Capital Securities o acciones ordinarias del emisor.

(iv) Carácter perpetuo. Las PPR tienen carácter perpetuo, es decir, no tienen vencimiento. Sin perjuicio de ello, el emisor está facultado para acordar la amortización total o parcial de las PPR a partir del 28 de marzo de 2013. Asimismo, con anterioridad a esa fecha, el emisor podrá amortizar totalmente la emisión, si concurre cualquiera de los supuestos (referidos a cambios en el régimen fiscal) establecidos en el apartado II.11.1.2 del Folleto Informativo.

(v) Prelación. En los supuestos de liquidación y disolución de Endesa Capital Finance, LLC, las PPR se situarán, a efectos del orden de prelación de créditos por delante de las acciones ordinarias del Emisor, pari passu con cualquier otra serie de Preferred Capital Securities del emisor, si las hubiere, con el mismo rango que las PPR y, por detrás de todos los acreedores (comunes y subordinados) del emisor. 
bancarias tienen voluntad de financiarse con instrumentos financieros privilegiados, pero les resultan más ventajosas las emisiones foráneas, que las realizadas según la legislación española.

La normativa internacional y comunitaria de control de solvencia de ciertas entidades (bancos, entidades de crédito, entidades de seguro y sociedades y agencias de valores) establece que la financiación subordinada solo es computable dentro de los recursos de capital de peor calidad (Tier two) cuando, entre otras cosas, presente una cierta estabilidad. En nuestro Derecho, al igual en el comunitario, se fija en cinco ańos la duración mínima de la financiación subordinada computable ${ }^{55}$. Por este motivo, en las PPR realizadas por cotizadas espańolas a través de filiales domiciliadas en paraísos fiscales, el emisor suele reservarse la facultad de rescatar solo a partir de cinco años. De esta forma, la emisión computa como recurso propio para el cálculo de la ratio de solvencia, es decir, para la cobertura general de riesgos.

Las PPR emitidas por sociedades filiales domiciliadas en paraísos fiscales de las entidades cotizadas españolas tienen como característica el rescate a voluntad de la dominante. En estos casos, la sociedad emisora se limita a servir de cauce para emitir activos financieros garantizados con todo el patrimonio de la emisora.

Las PPR se negocian en el mercado de la Asociación de Intermediarios en Activos Financieros (AIAF), denominado "AIAF, Mercado de Renta Fija". La negociación de las PPR en el citado mercado "de renta fija" fue autorizada mediante acuerdo del Consejo de la CNMV de 21 de octubre de 1998, "ampliándose así el elenco de activos que podían ser admitidos y negociados en él: cédulas, bonos y participaciones hipotecarias, obligaciones con o sin garantía real y subordinadas, bonos con o sin garantía real y subordinados, bonos matador, bonos de titulización, pagarés de empresa y warrants" 56 . Las PPR "combinan un riesgo intermedio entre renta fija y renta variable, con una rentabilidad superior a la de las obligaciones" 57 .

Las emisiones de PPR han sido efectuadas por filiales domiciliadas en el extranjero, con garantía solidaria e irrevocable de la matriz. Normalmente se trata de filiales constituidas en paraísos fiscales, al amparo de ordenamientos societarios de corte estadounidense con objeto de captar recursos en los mercados internacionales de capitales que puedan com-

Art. 4.3 de la Directiva del Consejo de 17 de abril de 1989 relativa a los fondos propios de las entidades de crédito, art. 22 del R.D. 1343/1992, norma 8.a de la Circular del Banco de Espańa 5/1993, y Circular 3/2008, de 22 de mayo, del Banco de Espańa, a entidades de crédito, sobre determinación y control de los recursos propios mínimos.

56 Reglamento AIAF, art. 8.

57 CNMV (1998) "Memoria ańo 1998", Informe Anual sobre Mercados de Valores. Madrid: CNMV, p. 47. 
putarse, bajo determinadas condiciones, como fondos propios de dichas entidades de crédito ${ }^{58}$.

\section{4) PARTICIPACIONES PREFERENTES EMITIDAS DE FORMA DIRECTA}

Las PPR no tienen reflejo en el ordenamiento jurídico español hasta julio de 2003, fecha de entrada en vigor de la Ley 19/2003. Sin embargo, existe otra fecha, noviembre de 1998, clave para estudiar la evolución de la figura. En ese momento, se produjo la primera emisión de PPR por parte de una empresa espańola destinada a inversores de otro mercado ${ }^{59}$; a partir de ahí se multiplicaron este tipo de emisiones.

Con estos datos, es posible identificar tres periodos según las posibilidades de emisión de PPR dictadas por la legislación y la práctica española. En cada una de estas tres fases son aplicables distintas modalidades de PPR. Hasta noviembre de 1998 se utilizaban únicamente PPR emitidas de forma indirecta en mercados internacionales por empresas extranjeras. De noviembre de 1998 a julio de 2003 se utilizaban las figuras anteriores $y$ las PPR emitidas de forma indirecta en mercados internacionales por empresas españolas. Desde julio de 2003 existen tres posibilidades de emisión: las PPR emitidas de forma indirecta en mercados internacionales por empresas extranjeras, las PPR emitidas de forma indirecta en mercados internacionales por empresas españolas, y como novedad, las PPR emitidas de forma directa en mercados nacionales por empresas espańolas.

La reforma parcial del TRLSA realizada en la LRLMV de 1998 (Reforma de la Ley 24/1988, de 28 de julio, del Mercado de Valores) intentó potenciar la emisión de acciones (o participaciones sociales) preferentes,

58 Siguiendo con el ejemplo de ENDESA, el Folleto Informativo de la emisión de PPR utiliza los siguientes términos: (a) "participaciones preferentes", para hacer referencia a los valores objeto del Folleto. (b) "Preferred Capital Securities", para hacer referencia al conjunto integrado por las participaciones preferentes y por cualesquiera otras participaciones preferentes que, en su caso, pueda emitir el Emisor, y que estén garantizadas por ENDESA S.A. en los mismos términos que las participaciones preferentes. (c) "Preferred capital securities", para hacer referencia al conjunto de preferred capital securities que puedan ser emitidas por cualquier entidad filial de ENDESA S.A. y que estén garantizadas por ésta en los mismos términos que las "Preferred Capital Securities". (d) "Participaciones Ordinarias", para hacer referencia al capital social con derecho a voto del Emisor". ENDESA (2003): Estatutos sociales de "ENDESA Capital Finance, LLC."Madrid: Endesa, 2003, p. 5.

59 Las primeras PPR realizadas por una empresa espańola son las integrantes de la emisión realizada por el Banco Bilbao Vizcaya en noviembre de 1998, por medio de la empresa filial "Banco Bilbao Vizcaya nominee Ltd", realizada en las Islas Caimán y sujeta al Derecho británico. Esta emisión se realizó el mismo mes y ańo que la fecha de realización de la LRLMV, razón por la que no se intentaron regular en ese momento. A partir de esta emisión, se sucedieron otras, que se empezaron a dirigir al mercado espańol previo registro del folleto en la CNMV. Las emisiones de este tipo de valores mobiliarios han sido muy numerosas desde entonces. 
sin voto y rescatables. Esta reforma fracasó, pues no se emitieron más clases de acciones después de su entrada en vigor, respecto las que se emitían con anterioridad. Este fracaso se debe, fundamentalmente, a que coincidió en el tiempo con el gran éxito de la emisión de PPR en paraísos fiscales. Desde el 1998 se produce la emisión masiva de PPR en emisiones deslocalizadas por parte de las empresas y grupos espańoles, y muy pocas emisiones de clases de acciones o participaciones sociales.

Ante el poco éxito de la Reforma de 1998, la legislación española varía su estrategia. El legislador parte del hecho de que las emisiones de PPR se comercializaban en Espańa, porque las entidades de crédito las colocaban entre sus propios clientes. Ante esta situación, la CNMV obligó a la verificación administrativa de la emisión, ya que todos los Folletos de emisión deberían ser verificados y registrados por la CNMV aunque el emisor estuviera sujeto a Ley extranjera. Además autorizó a que estos activos financieros se negociasen como renta fija en el mercado AIAF junto a pagarés, cédulas hipotecarias y otros activos ${ }^{60}$.

Después de años de ser un instrumento utilizado pero no regulado, el Gobierno español decidió legislar las PPR. El Ejecutivo lo acompañó de una amnistía fiscal ${ }^{61}$ para las emisiones realizadas desde paraísos fiscales y que, a la vez, permitía su colocación en España. Con ello pretendía

60 Los Mercados Financieros Oficiales y Organizados en España son tres: Mercados de Renta Fija, Mercados de Renta Variable y Mercado de Derivados. A su vez existen dos Mercados de Renta Fija: Mercado de Renta Fija Privada (AIAF) y Mercado de Deuda Pública. Los mercados de Renta Variable están compuestos por las cuatro Bolsas de Valores (Madrid, Barcelona, Bilbao, Valencia). El Mercado de Derivados en Espańa es el Mercado de Futuros y Opciones (MEFF).

El AIAF o mercado de renta fija privada es un mercado secundario oficial y organizado, que acoge una variedad de activos de renta fija que cubren distintos plazos. Los Activos de Renta Fija Negociados en el AIAF son fundamentalmente de cinco tipos: pagarés de empresa, bonos y obligaciones, cédulas hipotecarias, emisiones titulizadas y PPR. Los pagarés están destinados a cubrir las necesidades a corto plazo, tanto de inversores como de emisores. Los bonos y obligaciones están concebidos para plazos de dos o más ańos y admiten distintas variantes en función de los flujos de interés. Las cédulas hipotecarias son emitidas por entidades de crédito, y tienen la peculiaridad de estar garantizadas por el total de préstamos hipotecarios que tienen en sus activos. La titulización consiste en emitir bonos respaldados con algún derecho de cobro que se posea en el activo; es un buen medio de financiación para las empresas no financieras. Y por último, las PPR, objeto de este apartado.

61 Si no se hubiera producido la amnistía, las entidades financieras habrían tenido que aprovisionar contra resultados esas cantidades y, quizás el sistema bancario espańol podría haberse tambaleado tras los problemas derivados de la crisis de Argentina y en general de toda Latinoamérica. Martín, C.: "El Congreso amnistía las emisiones de bancos y cajas en paraísos fiscales”, Diario El País, http://www.elpais.es/, 26 marzo 2003, p. 3. Visto ahora, quizás hubiese sido mejor que esto se hubiera producido porque así hubieran tomado decisiones estructurales que las hubiera situado en una mejor situación en la crisis de 2009. La amnistía fiscal, junto con el aporte de liquidez gubernamental de 2009, son manifestaciones de los privilegios de los intermediarios financieros recibidos del estado espańol. Aunque gran parte de los impuestos amnistiados no se cobrarían por la hacienda pública espańola, ni por el paraíso fiscal, sino por la de un tercer país. Cazorla Prieto/ Blázquez Lidoy (2007) 744. 
que las filiales que constituyeron empresas en otras naciones para emitir PPR, vengan a nuestro país. La Hacienda Pública española ha puesto en marcha su estrategia, pero son las empresas las que deciden sobre el lugar donde emiten los instrumentos finanieros, y si ya están emitidos, sobre si traerán a España las emisiones o no.

La Ley 19/2003, de 4 de julio, sobre "régimen jurídico de los movimientos de capitales y de las transacciones económicas con el exterior y sobre determinadas medidas de prevención del blanqueo de capitales" (Ley 19/2003) ${ }^{62}$, introduce una nueva D.A. segunda en la Ley 13/1985 (BOE 5/07/2003).

La D.A. tercera de la Ley 19/2003 establece los aspectos fundamentales que caracterizan el régimen legal y fiscal de las PPR y otros instrumentos de deuda. Para analizarlo, es necesario estructurar el apartado en cuatro partes: ámbito de aplicación de la normativa, requisitos para considerar a un instrumento financiero como PPR, régimen legal sustantivo de las PPR, y, por último, nuevo régimen fiscal especial aplicable a la emisión y titularidad de PPR.

\section{1.) ÁMBITo DE APLICACIÓN}

La D.A. tercera de la Ley 19/2003 establece que la regulación de las PPR en ella establecida será de aplicación: (i) a las emitidas por una entidad de crédito o por una entidad residente en Espańa o en un territorio de la UE que no tenga la condición de paraíso fiscal, cuya actividad u objeto social exclusivo consista en la emisión de PPR u otros instrumentos de deuda y cuyos derechos de voto correspondan en su totalidad, directa

62 Durante la tramitación del Proyecto de Ley se incorporaron diversas enmiendas que darían lugar a la citada Ley 19/2003. Durante la tramitación en el Congreso de los Diputados se presentó la enmienda número 19 del Grupo parlamentario socialista con el objeto de concretar una regulación financiero-fiscal de este instrumento financiero para poder realizar las emisiones desde Espańa, con el objeto, tal y como seńala la motivación de la enmienda, de "cumplir con las recomendaciones del Grupo de Acción financiero sobre el blanqueo de capitales (GAFI) y perseguir el fraude fiscal”, asimismo en la motivación de la enmienda se ańadía lo siguiente: "Para ello se exige a las entidades de crédito que informen a la Agencia Tributaria y a todas las instituciones supervisoras del mercado financiero acerca de la identidad e inversión realizada por los suscriptores de participaciones preferentes. Y a su vez, que la emisión de participaciones preferentes, que ha venido realizándose en el extranjero, se lleve a cabo en Espańa. De este modo, las sociedades emisoras, filiales de las entidades financieras, se domiciliarán en Espańa en lugar de hacerlo, como hasta ahora, en territorios que gozan de exención completa o de un régimen fiscal muy atenuado respecto al Impuesto sobre Sociedades". El objetivo de la enmienda era crear las condiciones jurídicas óptimas para que las emisiones se hicieran desde Espańa y no desde otros territorios, la contrapartida era la exigencia de información de la identidad e inversión realizada por los tenedores de PPR. En consecuencia se incorporó una D.A. tercera a la Ley 19/2003 que modificaba la Ley 13/1985, de 25 de mayo, de coeficientes de inversión, recursos propios y obligaciones de información de los intermediarios financieros, incorporándose a esta última Ley una D.A. segunda con el régimen jurídico financiero-fiscal de las PPR. 
o indirectamente, a una entidad de crédito dominante de un grupo o subgrupo consolidable de entidades de crédito; y (ii) a las emitidas por una sociedad residente en Espańa o en un territorio de la UE que no sea considerado paraíso fiscal y cuyos derechos de voto correspondan en su totalidad, directa o indirectamente, a entidades cotizadas que no sean de crédito.

Respecto al régimen fiscal y deberes de información en la emisión de PPR, será aplicable a otros instrumentos de deuda emitidos por una sociedad de las autorizadas para emitir PPR. En este caso, deberán cumplirse tres requisitos: cotización de tales instrumentos en un mercado organizado; exclusividad de actividad y objeto, en su caso, y, cuando se requiera; y por último, depósito permanente del importe de la emisión. La razón de esta extensión reside en que la necesidad de financiación ha llevado a las entidades de crédito y otras sociedades espańolas a emitir instrumentos de deuda en el exterior por volúmenes muy superiores a los de las $\mathrm{PPR}^{63}$.

\section{2.) CARACTERÍSTICAS}

La D.A. tercera de la Ley 19/2003 regula, además del régimen fiscal relativo a las PPR, las condiciones que tienen que cumplir dichas PPR para considerarse como recursos propios de las entidades de crédito y grupos de entidades de crédito ${ }^{64}$.

Los requisitos de índole financiera que han de tener las PPR son:

a) Ser emitidas por una entidad de crédito o por una entidad residente en Espańa o un territorio de la UE que no tenga la consideración de paraíso fiscal, que tenga como objeto exclusivo la participación de preferentes y que pertenezca en su totalidad a un grupo o subgrupo de entidades de crédito.

b) Cuando la emisión se realice por una entidad filial los recursos deberán estar depositados en la entidad de crédito dominante o en otra

63 En relación a las cuestiones mencionadas, la Dirección General de Tributos (DGT) en su consulta vinculante número V0173-05, adoptó una interpretación extensiva de la aplicación del régimen fiscal especial previsto en la Ley 19/2003, al admitir su aplicación respecto de otros instrumentos de deuda emitidos directamente por una entidad de crédito y no por medio de filiales instrumentales cuyo objeto exclusivo sea la emisión de PPR, siempre que tales instrumentos cumplan con los requisitos establecidos por la Ley 19/2003. A estos efectos, la consulta de la DGT considera, sobre la base de un informe de la Dirección General del Tesoro y Política Financiera, que el término "instrumento de deuda" debe abarcar a todo tipo de instrumentos distintos de aquellos que constituyen una participación en el capital propio de una entidad con independencia de su forma de rendimiento. Dirección General del Tesoro y Política Financiera: Cortes Generales. Diario de Sesiones del Senado, http://www. senado.es/legis8/publicaciones/html/textos/CS0344.html.

64 Existe por tanto una interrelación muy grande entre los requisitos de índole financiera y el régimen fiscal aplicable a las PPR. 
entidad del grupo, estando dicho depósito afecto a la compensación de pérdidas del grupo.

c) Los recursos obtenidos deberán estar depositados en su totalidad, descontados los gastos de gestión y emisión, y de forma permanente en la entidad de crédito dominante o en otra entidad del grupo.

d) Contar con la garantía solidaria e irrevocable de la entidad de crédito dominante o la entidad depositaria.

e) Otorgar el derecho a percibir una remuneración predeterminada de carácter no acumulativo, cuyo devengo esté condicionado a la existencia de beneficios distribuibles en la entidad de crédito dominante o su grupo.

f) No deben otorgar derechos políticos, salvo en los supuestos excepcionales que se establezcan en las condiciones de emisión.

g) No deben conceder derechos de suscripción preferente, y deben tener carácter perpetuo si bien se puede acordar la amortización anticipada a partir del quinto año desde su fecha de desembolso, previa autorización del Banco de España.

h) Cotizar en mercados secundarios organizados.

i) En los supuestos de liquidación o disolución u otros que den lugar a la aplicación de las prioridades contempladas en el Código de Comercio, de la entidad de crédito emisora o de la dominante del grupo o subgrupo consolidable de las entidades de crédito, las PPR deben dar derecho a obtener exclusivamente el reembolso del valor nominal junto con la remuneración devengada y no satisfecha y se situarán a efectos del orden de prelación de créditos, inmediatamente detrás de todos los acreedores, subordinados o no, de la entidad de crédito emisora o de la dominante del grupo o subgrupo consolidable de entidades de crédito y delante de los accionistas ordinarios.

j) En el momento de realizar una emisión, el importe nominal en circulación no podrá ser superior al $30 \%$ de los recursos propios básicos del grupo o subgrupo consolidable, incluido el importe de la propia emisión, sin perjuicio de las limitaciones adicionales que puedan establecerse a efectos de solvencia ${ }^{65}$.

\section{3.) RÉGIMEN LEGAL}

La Ley 19/2003 establece diversos aspectos para definir el régimen legal de las PPR.

65 Si dicho porcentaje se sobrepasara una vez realizada la emisión, la entidad de crédito deberá presentar ante el Banco de Espańa para su autorización un plan para retornar al cumplimiento de dicho porcentaje. El Banco de Espańa podrá modificar el citado porcentaje. 
a) Residencia habitual de las entidades emisoras y de las entidades dominantes. El legislador dio un vuelco a la situación regulada hasta ese momento. A partir de su entrada en vigor, las nuevas emisiones de PPR que quieran beneficiarse del régimen legal y fiscal establecido en la Ley 19/2003 deberán ser realizadas por una entidad de crédito o por una entidad residente en Espańa o en un territorio de la UE que no tenga la condición de paraíso fiscal, en cuyo caso sus derechos de voto deberán pertenecer íntegramente (directa o indirectamente) a una entidad de crédito o a una sociedad cotizada no de crédito. La razón de la incorporación a este régimen de las emisiones efectuadas por sociedades cotizadas no de crédito, efectuada a través de una enmienda en el Senado, radica en la conveniencia de permitir, entre otros, a los grandes grupos cotizados espańoles, financiarse y estructurar adecuadamente sus recursos propios a efectos de "rating" y de las exigencias de determinadas operaciones financieras ${ }^{66}$. Todo lo anterior hace referencia a la sociedad emisora, respecto a la entidad dominante, la Ley 19/2003 menciona expresamente que la norma será también aplicable en los supuestos en que la entidad dominante se rija por el derecho de otro Estado, por lo que puede entenderse que el régimen legal de las PPR será aplicable independientemente del lugar de residencia de la entidad dominante.

b) Derechos de voto y objeto social del emisor. Los derechos de voto de la sociedad emisora deben corresponder íntegramente (de forma directa o indirecta) a una entidad de crédito dominante de un grupo o subgrupo consolidable de entidades de crédito (o a una entidad cotizada que no sea de crédito) y cuya actividad u objeto exclusivo sea la emisión de PPR y/u otros instrumentos de deuda, lo que da carta de naturaleza a la extendida práctica de estructurar el capital de la sociedad emisora de manera que los derechos de voto pertenecieran a otra entidad de crédito (o sociedad cotizada) titular de la mayor parte del capital social (pero de una reducida parte de los recursos propios) y que las PPR no llevaran aparejado derecho de voto, salvo en circunstancias excepcionales ${ }^{67}$.

c) Depósito. La Ley 19/2003 ha establecido mecanismos para que los fondos obtenidos mediante la emisión de PPR estén centralizados para garantizar su efectiva equiparación a los recursos propios, a efectos de protección de acreedores. Así, si la emisión ha sido efectuada por una filial, los recursos obtenidos mediante la emisión deberán ser íntegramen-

66 Nada se especifica en la Ley acerca de la posibilidad de que la emisión se efectúe a través de una sucursal establecida en el territorio de un Estado Miembro de la UE diferente al de residencia de la entidad emisora, pero, en principio, habrá que entender que resulta posible a la luz de la jurisprudencia del Tribunal de Justicia de las Comunidades Europeas (TJCE). título otras medidas, como la constitución de un sindicato o asociación de titulares de PPR. FernándeZ del Pozo (2005) 614-615. 
te depositados (una vez descontados gastos de emisión y gestión) en la entidad dominante o en otra entidad del grupo o subgrupo consolidable, que les podrá dar el destino que estime conveniente. En cualquier caso, la Ley 19/2003 obliga a que dicho depósito sea aplicado por la entidad depositaria a la compensación de pérdidas en su liquidación o en el saneamiento general de aquella o de su grupo o subgrupo consolidable, en el supuesto de que agoten las reservas y se hubiera reducido a cero el capital ordinario. Para los supuestos en que la emisión se realice por una filial, las PPR deberán contar con la garantía solidaria e irrevocable de la entidad dominante o de la entidad depositaria. También se exigen los requisitos de depósito permanente y garantía de la entidad dominante para la emisión de otros instrumentos de deuda cuando se pretenda que se beneficie del mismo régimen fiscal.

d) Remuneración. La remuneración de las PPR deberá estar predeterminada ${ }^{68}$, sin que pueda tener carácter acumulativo ${ }^{69}$. La Ley 19/2003 hace depender la remuneración de la existencia de beneficios distribuibles, aunque diluye este requisito en la medida en que este se entenderá cumplido si existen beneficios distribuibles en la entidad de crédito dominante o en el grupo o subgrupo consolidable, al tratarse de un vehículo específico para efectuar la emisión.

e) Derechos políticos. La Ley 19/2003 no permite, a los titulares de las PPR, el ejercicio de los derechos políticos, salvo en aquellos casos expresamente previstos en las condiciones de la emisión. Su concesión se limita a supuestos en que los titulares de PPR vean peligrar la rentabilidad de su inversión, ya sea de forma directa (en el supuesto de falta de pago de una serie de remuneraciones), o de forma indirecta (reducciones de capital, salvo cuando sean por imperativo legal, ya que es la cifra de capital social la que supone una última garantía para los inversores).

f) Derechos de suscripción preferente. La Ley 19/2003 establece que las PPR carecerán de derecho de suscripción preferente respecto de futuras emisiones. Esta medida es correcta pues las PPR no suponen una participación en el capital social de la sociedad ni son partes alícuotas del mismo, por lo que no es necesario establecer mecanismos antidilución para las mismas.

g) Duración. Las PPR deberán tener carácter perpetuo, sin embargo, la Ley 19/2003 prevé que sean amortizables anticipadamente, previa autorización por parte del Banco de España, a partir del quinto año desde su fecha de desembolso ${ }^{70}$. La autorización del Banco de España no será

La Ley 19/2003 no establece en función de qué magnitud dando, por tanto, libertad al respecto.

69) Esto diferencia a las PPR de figuras con características similares, como las acciones sin voto.

70 Aunque la Ley 19/2003 omite toda referencia a la persona a quien corresponde la iniciativa en la amortización, la práctica indica que dicha amortización se producirá a instancias de la 
necesaria si la emisión de PPR la efectúa una sociedad cuyos derechos de voto sean íntegramente (directa o indirectamente) propiedad de una sociedad cotizada que no sea una entidad de crédito, puesto que en estos casos se trata de sociedades no sujetas a coeficientes de solvencia y recursos propios mínimos y el Banco de Espańa carece de la facultad de supervisión de la citada entidad o de su matriz.

h) Cotización. La Ley 19/2003 exige que las PPR coticen en un mercado secundario organizado. Como no especifica nada acerca de su nacionalidad, entendemos que la cotización en mercados organizados extranjeros es suficiente para cumplir este requisito.

i) Orden de prelación. En los supuestos de liquidación, disolución o insolvencia del emisor o de su entidad dominante del grupo o subgrupo consolidable, las PPR darán derecho a su titular a obtener únicamente el reembolso de su valor nominal junto con la remuneración devengada y no satisfecha. Por lo que respecta al orden de prelación de créditos, las PPR están conceptuadas, al menos a efectos de las entidades sujetas a la supervisión del Banco de Espańa, como recursos propios de la sociedad con prelación sobre el capital ordinario y en consecuencia se sitúan detrás de todos los acreedores de la entidad emisora o de la entidad dominante (ya sean subordinados o no ${ }^{71}$, pero delante de los accionistas ordinarios o, en el caso de las cajas de ahorros de los cuotapartícipes.

j) Límite cuantitativo. La Ley 19/2003 establece un límite cuantitativo a la emisión de PPR en función de sus recursos propios. El importe nominal de las PPR en circulación no podrá superar, en el momento de realizar una emisión, el 30\% de los recursos propios básicos del grupo o subgrupo consolidable de la entidad de crédito, incluyendo en dicho cómputo las PPR que formen parte de la nueva emisión. Dicho porcentaje puede ser modificado por el Banco de España. Sin perjuicio de lo anterior, se permite expresamente que se puedan establecer limitaciones adicionales derivadas de criterios relativos a la solvencia de las entidades de crédito $^{72}$. El límite cuantitativo (y por lo tanto la facultad de Banco de España de modificarlo) no será de aplicación si la emisión de PPR es

entidad emisora.

71 Por detrás de la deuda calificada como senior, pero incluso, detrás de la calificada como junior.

72 Sin embargo, se prevé que se produzcan circunstancialmente excesos sobre el límite del $30 \%$, derivados por ejemplo de pérdidas que reduzcan los fondos propios y ocasionen que las PPR excedan del límite del 30\%. En este supuesto, la entidad correspondiente deberá presentar ante el Banco de Espańa para su autorización un plan para eliminar dicho exceso. No se especifica el plazo de que dispone la entidad de crédito para presentar dicho plan ni el plazo de que dispone el Banco de Espańa para autorizarlo o los criterios que puede aducir para denegar la autorización, extremos que quedan pendientes de desarrollo, aunque puede considerarse de aplicación analógica la regulación establecida para casos similares. art. 34 del R.D. 1343/1992, de 6 de noviembre. 
efectuada por una sociedad cuyos derechos políticos sean íntegramente propiedad de una entidad cotizada que no sea entidad de crédito.

\section{4.) RÉGIMEN FISCAL} siguientes:

Desde el punto de vista fiscal ${ }^{73}$, las características de las PPR son las

a) La remuneración tendrá la consideración de gasto deducible para la entidad emisora.

b) Las rentas derivadas de las PPR se calificarán como rendimientos obtenidos por la cesión a terceros de capitales propios de acuerdo con lo previsto en el art. 23.2 de la Ley $40 / 1998^{74}$.

c) Los rendimientos generados por el depósito efectuado por el emisor en la entidad dominante $\mathrm{u}$ otra del grupo no están sometidos a retención, aplicando en su caso la exención prevista para las cuentas de no residentes de acuerdo con lo seńalado en el art. 13.1.e de la Ley $41 / 1998^{75}$.

d) Las rentas derivadas de PPR obtenidas por sujetos pasivos del Impuesto sobre la Renta de los no Residentes quedarán exentas en los mismos términos establecidos para los rendimientos derivados de la Deuda Pública.

e) Las operaciones derivadas de la emisión estarán exentas de la modalidad de Operaciones Societarias del ITP y AJD ${ }^{76}$.

El régimen fiscal se aplica tanto a las PPR como o a otros instrumentos de deuda emitidos por una sociedad residente en Espańa o en un territorio de la UE que no tenga la condición de paraíso fiscal y cuyos derechos de voto correspondan en su totalidad directa o indirectamente a entidades cotizadas que no sean de crédito.

73 La Ley 19/2003 es sobre todo, fiscal, como puede observarse en su denominación para evitar el blanqueo de capitales: Ley 19/2003, de 4 de julio, "sobre régimen jurídico de los movimientos de capitales y las transacciones económicas con el exterior y sobre determinadas medidas de prevención del blanqueo de capitales".

74 Dicha mención está referida al R.D. Legislativo 3/2004, de 5 de marzo por el que se aprueba el TRLIRPF.

75 Dicha mención está referida al R.D. Legislativo 5/2004, de 5 de marzo por el que se aprueba el Texto Refundido de la Ley del Impuesto sobre la Renta de los no Residentes.

76 Se completa el tratamiento relativo a las operaciones societarias con lo dispuesto en la D.A. 38.a de la Ley 62/2003 de 30 de diciembre, de acompańamiento a los Presupuestos Generales del Estado del ańo 2004, que incorpora una disposición en el régimen de referencia de las PPR, que establece la exención de la modalidad de las operaciones societarias del ITP y AJD para los traslados a Espańa de la sede de la dirección efectiva o del domicilio social de sociedades cuya actividad y objeto social exclusivo consistan en la emisión de PPR y/u otros instrumentos financieros y que estuvieran constituidas antes de 6 de julio de 2003, fecha de entrada en vigor de la Ley 19/2003. 
El régimen tributario resultante de la Ley 19/2003 se aplica también a las PPR y otros instrumentos de deuda que se hubieran emitido con anterioridad a la aprobación de la Ley por cualquier entidad residente o no, de acuerdo con lo dispuesto en la D.T. $2^{\text {a }}$ de la Ley 19/2003; siempre y cuando la actividad exclusiva de la entidad sea la emisión de PPR y/u otros instrumentos de deuda y cuyos derechos de voto correspondan en su totalidad directa o indirectamente a una entidad de crédito dominante de un grupo o subgrupo consolidable.

El régimen fiscal es completo porque tiene influencia sobre cinco impuestos. El primero de ellos es el Impuesto sobre Sociedades. Por lo que respecta a la entidad emisora, la remuneración a pagar a los titulares de las PPR u otros instrumentos de deuda será considerada gasto deducible. Idéntica consideración tendrán las comisiones abonadas por la garantía concedida por la entidad depositaria, siempre y cuando se respete el principio de valoración en condiciones de mercado. Por su parte, se integrarán en la base imponible de la sociedad emisora las rentas que obtenga del depósito efectuado con los fondos obtenidos con la emisión de deuda. Es previsible que el beneficio imputable a dicha entidad no sea muy significativo, en cuanto que generalmente habrá sido creado como un mero vehículo de obtención y canalización de fondos en favor de otras vinculadas con ella. Al optar el legislador por ventajas fiscales distintas de la fijación de un tipo reducido en el Impuesto de Sociedades ${ }^{77}$, se evita la existencia de eventuales problemas ante las autoridades comunitarias ${ }^{78}$ a la vez que se respetan los compromisos adquiridos por Espańa ante el resto de estados miembros en el ámbito del Código de Conducta sobre la tributación del beneficio empresarial.

En segundo lugar, tiene influencia sobre el IRPF. Las rentas derivadas de la titularidad de estos instrumentos de deuda por personas físicas residentes en España estarán sujetas a retención y se integrarán en la base imponible del IRPF como rendimientos derivados de la cesión a terceros de capitales propio.

También tiene influencia sobre el Impuesto sobre la Renta de No Residentes. Las rentas que obtengan los sujetos pasivos que carezcan de establecimiento permanente en Espańa, y siempre que no se perciban a través de los territorios calificados como paraíso fiscal por la normativa espańola, estarán sujetas pero exentas del mismo, en los términos previstos para la percepción por aquellos de rendimientos procedentes de la titularidad de la Deuda Pública. Además, si la entidad emisora es no residente, los rendimientos derivados del depósito efectuado con una so-

Durante el proceso parlamentario llegó a barajarse la posibilidad de introducir ventajas fiscales distintas de la fijación de un tipo reducido en el Impuesto de Sociedades.

78 Las autoridades comunitarias podrían haber considerado dicha medida como una ayuda de Estado encubierta. 
ciedad residente o, en determinadas condiciones, con un establecimiento permanente ubicado en territorio espańol estarán nuevamente exentos de retención, en los términos previstos para los rendimientos de las cuentas de no residente.

Respecto al Impuesto sobre el patrimonio, las personas físicas residentes quedarán sujetos a este impuesto por la titularidad de dichos valores, siendo su base imponible el valor de negociación medio en el cuarto trimestre de cada año ${ }^{79}$. Por su parte, las personas físicas no residentes estarán exentas de este impuesto ${ }^{80}$.

La Ley 19/2003 también tiene influencia sobre el ITP y AJD. Si la entidad emisora es española (o si la emisión se efectúa por medio de una sucursal radicada en Espańa), las operaciones derivadas de la emisión de las PPR estarán exentas de gravamen por la modalidad de Operaciones Societarias ${ }^{81}$.

La Ley 19/2003 impone la obligación, a las entidades dominantes, de informar a la Administración Tributaria y, en su caso, a las instituciones encargadas de la supervisión financiera, acerca de la actividad desarrollada por las entidades emisoras y de la identidad de los titulares de los valores. En el caso de que las entidades dominantes o cotizadas no residan en España, las obligaciones de información que la Ley les impone son atribuidas por el R.D. 1778/2004 a los intermediarios financieros que participen en la suscripción, comercialización, depósito, canje, conversión, cancelación y reembolso de estos valores, en lugar de a sus propias filiales emisoras. La información a facilitar consistirá en la identidad de los sujetos intervinientes en la operación, su domicilio, NIF, la identificación de los valores, el importe y la fecha de su emisión. Por lo que se refiere a las emisiones efectuadas por entidades de crédito o cotizadas residentes en Espańa por medio de filiales establecidas en otros Estados de la UE, el R.D. 1778/2004 atribuye las obligaciones de información a aquellas, quienes deberán velar por que sus filiales emisoras no residentes cumplan una serie de requisitos documentales exclusivamente a efectos de la normativa tributaria espańola.

79 De acuerdo con la relación que publique el Ministerio de Economía y Hacienda (www.meh. es).

80 A tenor de lo dispuesto en el art. 4.7 de la Ley del Impuesto sobre el Patrimonio en relación con lo establecido en el art. 14 del Texto Refundido de la Ley del Impuesto sobre la Renta de No Residentes.

81 Asimismo, la Ley de Acompańamiento para el ańo 2004 (Ley 62/2003 de 30 de diciembre, de medidas fiscales, administrativas y del orden social) introdujo una nueva exención en la modalidad de operaciones societarias, en relación con el traslado a Espańa de la sede de la dirección efectiva o domicilio social de sociedades cuyo objeto social exclusivo consista en la emisión de PPR u otros instrumentos financieros, y hubiesen sido constituidas antes de la entrada en vigor de la Ley 19/2003. 
Por último, la Ley 19/2003 regula el régimen fiscal transitorio aplicable a las emisiones de PPR anteriores a su entrada en vigor. A tenor de la D.T. segunda de esta Ley, las emisiones de PPR y de deuda realizadas antes de su entrada en vigor ( 6 de julio de 2003) podrán beneficiarse del nuevo régimen tributario, cualquiera que sea la residencia fiscal de la entidad emisora, a condición de que cumplan dos condiciones. La primera es que su actividad exclusivamente consista en la emisión de PPR y/u otros instrumentos financieros. La segunda es que sus derechos de voto correspondan en su totalidad, directa o indirectamente, a una entidad de crédito dominante de un grupo o subgrupo consolidable de entidades de crédito o a sociedades cotizadas.

\section{5.) EVALUaCión de La CONSECUCión DE LAS FINALIDADES}

La Ley 19/2003 tiene cuatro objetivos: (1) establecer unos requisitos claros para el reconocimiento de la legitimidad, con arreglo al Derecho español, de la emisión indirecta de PPR a través de filiales extranjeras, (2) regularizar la situación fiscal de las emisiones de PPR realizadas antes de esta Ley, (3) estimular la localización en España de las SPV emisoras de próximas PPR, y (4) estimular la vuelta a la legislación espańola de las sociedades instrumentales emitidas en el extranjero, mediante su traslado de domicilio a Espańa.

La Ley 19/2003 regula dos tipos de instrumentos financieros: las PPR y las "otras preferentes". De la misma forma contempla, tanto la emisión directa como indirecta de $\mathrm{PPR}^{82}$. En cuanto al emisor, la Ley regula tanto la emisión por entidad sujeta a legislación española, como por sociedad extranjera residente en el territorio de la U.E. que no tenga la condición de territorio de baja tributación.

Toda regulación de híbrido financiero debe definir el encuadre normativo del título. Para las PPR es necesario definir tres perspectivas. Desde la perspectiva jurídica sustantiva del Derecho de sociedades, es necesario conocer si están sujetos a la normativa que rige el capital social, a la prevista para la emisión de obligaciones, o a una diferente. Además debe resolverse si debe incorporarse al patrimonio neto a efectos sustantivos (a efectos de aplicación de resultados, reducción forzosa de capital y disolución por pérdidas). Desde la perspectiva de la normativa de control de la solvencia de las entidades financieras, los problemas de calificación del instrumento se basan en la determinación de la computabilidad del mismo dentro de las diversas categorías de recursos propios. Fundamentalmente, es necesario conocer si cada uno de las PPR cumple los requisitos

82

Regula como modelo de referencia la emisión indirecta por sociedad dominante de un grupo a través de una SPV. 
para su cómputo dentro del capital básico o Tier one. Desde la perspectiva fiscal, interesa conocer si su remuneración tiene la consideración de gasto deducible (como ocurre con los intereses de préstamos) para la entidad emisora en el impuesto de sociedades ${ }^{83}$.

Desde el punto de vista sustantivo mercantil, la Ley 19/2003 elude considerar a las PPR como un valor mobiliario, conceptualizándolos como instrumento financiero. El término instrumento financiero, categoría distinta de los valores negociables ${ }^{84}$, fue definido en nuestra legislación en la LRLMV, y es concordante tanto con la legislación mercantil italiana $^{85}$, como con la categoría contable establecida en la IAS $32^{86}$ e IAS $39^{87}$. A la luz de su normativa, las PPR no son acciones (ni participaciones sociales), ni acciones privilegiadas, ni acciones sin voto, ni acciones rescatables. La Ley, al referirse a las PPR, nunca habla de acciones sino de participaciones, ni de accionistas sino de titulares, y nunca menciona a su remuneración como dividendo sino como remuneración predeterminada del instrumento financiero. Además, la Ley permite su cotización en "mercados secundarios organizados", y no requiere que sea en "la Bolsa" como ocurría con las acciones de la sociedad cotizada. Al no ser consideradas como acciones (ni participaciones sociales), jurídicamente son, no cabe otra alternativa, deuda. Pero estas deudas no deben cumplir, no hay razón para ello, el régimen de las obligaciones establecidas en el TRLSC, ya que las PPR pueden conferir a sus titulares derechos políticos, mientras que la legislación espańola solo confiere a los obligacionistas los derechos de participación y voto en las reuniones del sindicato. Pero entonces, si las PPR no son acciones ni obligaciones, debemos especificar cuál es su naturaleza. Las posibilidades son dos: una emisión de deuda más o un

83 Nuestro artículo diferencia las dos dimensiones contable y fiscal. Este es el camino correcto, aunque no todos los textos piensan igual. Esta confusión es incurrida, incluso, en los organismos de contabilidad. Para AECA, las PPR son un instrumento parecido a una deuda, si bien el hecho de que se seńale ad hoc la deducibilidad de los intereses devengados en el impuesto sobre sociedades, al ser un aspecto general de todos los préstamos produce dudas sobre si el legislador lo está configurando como un fondo propio con remuneración deducible en el impuesto de sociedades. Asociación Espańola de Contabilidad y Administración de Empresas (AECA): Calificación contable de instrumentos financieros: Distinción pasivo patrimonio neto, documentos 25 Principios contables, septiembre, AECA, Madrid, 2008, p. 41.

84 A pesar de su diferenciación, el art. 2 de la LMV establece que a los instrumentos financieros se les aplicarán las reglas previstas para los valores negociables.

85 El Dlgs 24-2-2003 permite a la sociedad anónima recurrir a una tipología amplia de instrumentos financieros, ya no restringidos al binomio acciones-obligaciones, sino extendida a una amplia gama de instrumentos, calificados algunos de ellos como instrumentos financieros.

86 International Accounting Standard Board (IASB) (1995) "International Accounting Standard no 32", Financial instruments: Disclosures and presentation, june, London.

87 IASB (1998) “International Accounting Standard no 39”, Financial Instruments: Recognition and measurement, december, IASB, London. 
nuevo híbrido financiero entre acciones y obligaciones. En nuestra opinión, las PPR son una figura financiera híbrida entre acciones y obligaciones ${ }^{88}$.

En el orden administrativo, la legislación ha incluido dentro de los requisitos de computabilidad Tier 1, a los híbridos de capital emitidos a través de filiales en paraísos fiscales por las entidades de crédito españolas.

El tratamiento fiscal de la figura, proporciona un cauce adecuado para hacer atractiva la domiciliación en España de las emisiones de PPR por grupos extranjeros, procurando paliar el fenómeno de la deslocalización fiscal. Esto se intenta conseguir por medio del establecimiento de cuatro medidas:

1) Los pagos efectuados por la sociedad emisora a los titulares de las PPR serán gastos deducibles en el impuesto de sociedades de la sociedad emisora.

2) El pago de las remuneraciones a los titulares de los valores podrá efectuarse libre de cualquier retención.

3) Las rentas derivadas de las PPR obtenidas por inversores sujetos pasivos de dicho impuesto que no actúen en Espańa mediante establecimiento permanente, estarán exentas de tributación en el impuesto sobre la renta de los no residentes, en las mismas condiciones establecidas para los rendimientos derivados de la deuda pública.

4) Las operaciones derivadas de la emisión de PPR estarán exentas de la modalidad de OS del ITPyAJD.

Estas ventajas fiscales son muy similares a las que tenían las emisoras e inversores en ausencia de norma, por lo que se puede afirmar que el legislador intenta atraer a la Hacienda Pública espańola las emisiones por medio de la concesión de asimilables ventajas fiscales. Con las tres primeras medidas se pretende atraer a la legislación española las futuras emisiones de PPR; con la cuarta medida, junto a las anteriores, se intenta provocar el cambio de domicilio social, hacia una localidad espańola, de las empresas que ya tenían PPR emitidas. Por tanto, la Ley 19/2003 intenta, por un lado, atraer las inversiones futuras, sean de empresas españolas y extranjeras ${ }^{89}$, y por el otro, domiciliar en Espańa las empresas vehículo que ya tienen emitidas previamente $\mathrm{PPR}^{90}$.

88 Este razonamiento está apoyado en FernáNDEZ DEL Pozo, quien defiende la existencia de híbridos financieros autónomos, y como ejemplo pone la regulación espańola de PPR a la que se les concede "un marco regulatorio específico" Fernández del Pozo, L. (2005) Las participaciones preferentes: un hibrido supletorio del capital social. Madrid: Thompson Civitas, p. 81. Así lo ha entendido el Derecho italiano, sobre el que el legislador espańol se ha guiado para definir la regulación sobre las PPR.

En 2004, Banco Popular, Bankinter, BBVA, Caixa Galicia, Caja Rioja y SCH, crearon filiales para la emisión de PPR desde Espańa.

90

El éxito de la segunda medida se está produciendo muy lentamente. En enero de 2005 se 
Sin embargo, las empresas y grupos españoles han emitido un volumen similar de emisiones de las PPR emitidas de forma directa y de clases de acciones, desde la Ley 19/2003, respecto a las emitidas con anterioridad de la entrada en vigor de la citada Ley.

\section{CONCLUSIONES}

1.- En este artículo no se analiza las acciones ni participaciones sociales privilegiadas reguladas en el TRLSC, sino otro tipo de emisiones, que no fueron reguladas en la legislación española hasta la Ley 19/2003. Estos híbridos presentan una terminología diversa: emisiones preferentes, participaciones preferentes o incluso acciones preferentes en el sistema angloamericano.

La nomenclatura "participaciones preferentes" es la traducción al idioma castellano de los instrumentos financieros "preference/preferred shares". La traducción omite intencionadamente el término acción, sin duda para alertar al inversor del riesgo de confusión con las acciones y participaciones sociales. Sin embargo, las primeras PPR emitidas eran en origen verdaderas acciones, aunque sujetas a la legislación de los países en que estaba domiciliada.

En la actualidad, las empresas españolas pueden seguir financiándose con híbridos emitidos por medio de sociedades domiciliadas en otros

produjo el traslado de la sociedad instrumental "Caixa de Terrasa preference Ltd." desde las Islas Caimán a Espańa.

En 2009, Caja Castilla-La Mancha (CCM) trasladó la sede de su sociedad de PPR desde las Islas Caimán a Espańa. De esta forma, la sociedad antes denominada 'CCM Preference Limited' adquiere la nacionalidad espańola, aunque mantiene su personalidad jurídica. Desde ese momento, 'CCM Preferentes' quedó inscrita en el Registro Mercantil de Cuenca y adaptó su estatuto jurídico al Derecho espańol vigente, al TRLSA y a la Ley sobre régimen jurídico de las transacciones económicas con el exterior y sobre determinadas medidas de prevención del blanqueo de capitales. Estos cambios no implicaron una nueva emisión de los valores de las PPR, sino que quedaron sujetos a la legislación espańola por lo que, desde ese momento debieron cumplir con los coeficientes de inversión, recursos propios y obligaciones de información a los ciudadanos.

En 2010, Caja Mediterráneo (CAM) ha liquidado CAM International Limited, la última de las sociedades que mantenía en el paraíso fiscal de las Islas Caimán con el objetivo de captar fondos de inversores extranjeros, según recoge el último informe semestral remitido por la caja a la Comisión Nacional del Mercado de Valores (CNMV). De esta forma, la entidad pone fin a 12 ańos de presencia en la colonia británica con los que contribuyó a financiar la expansión de la CAM por todo el territorio nacional. De hecho, la caja alicantina llegó a tener hasta tres sociedades distintas operando en las islas, la citada CAM Internacional, CAM Capital y CAM Global Finance.

También en 2010, la entidad financiera Bancaja Eurocapital Finance S.A. ha trasladado su sede social desde las Islas Caimán a Espańa tras realizar la correspondiente inscripción en el Registro Mercantil de Castellón. 
países, cuyo objeto exclusivo es la emisión de participaciones preferentes, cumpliendo las leyes de esos países. Pero tras la entrada en vigor de la Ley 19/2003, existen otros híbridos distintos, denominados expresamente en la legislación española como "participaciones preferentes", emitidos por sociedades españolas y regulados por el Derecho español.

De esta forma coexisten tres tipos de participaciones preferentes (PPR). El primero son las participaciones preferentes traducción al castellano del instrumento financiero "preference/preferred shares". Estas participaciones preferentes están reguladas por las Leyes de los países en que estén domiciliadas. La consideración jurídica internacional es claramente de acciones (shares). En este artículo se propone denominarlos o "PPR emitidas de forma indirecta" o "PPR no reguladas por la Ley 19/2003". El segundo son las PPR reguladas por la Ley 19/2003. Su calificación es contraria a la anterior porque en ningún lugar de la legislación son consideradas acciones. Las dos denominaciones propuestas en este artículo son "PPR emitidas de forma directa" o "PPR reguladas por la Ley 19/2003". El tercero son las "Otras preferentes", también reguladas por la Ley 19/2003. En ningún lugar de la legislación son consideradas acciones o participaciones sociales. Este artículo propone mantener la denominación "Otras preferentes".

Las PPR emitidas por empresas domiciliadas en otros países, cuya dominante es una empresa española, no reguladas por la Ley 19/2003 ("PPR emitidas de forma indirecta") deben cumplir lo establecido en la legislación del país en que esté domiciliada. En la emisión de "PPR emitidas de forma indirecta " intervienen dos sociedades: la sociedad emisora, que es una sociedad instrumental o vehículo, domiciliada en un país extranjero, y la sociedad garante de la emisión, domiciliada en Espańa, que es dominante de la instrumental. La emisión de "PPR emitidas de forma indirecta" tiene ventajas mercantiles para la sociedad garante ya que puede emitir acciones sin que sea necesario cumplir algunos requisitos societarios que hubiesen sido inexcusables si se hubiesen emitido directamente acciones. Los requisitos que no son cumplidos en el caso de realizar la emisión indirecta de PPR son dos: la aprobación de la operación por parte de la Junta General de Accionista (art. 297.1 TRLSC) y la exclusión del derecho preferente de suscripción a los accionistas (art. 506 TRLSC).

Por su parte, las PPR reguladas en la Ley 19/2003 ("PPR emitidas de forma directa") deben ser formalizadas en escritura pública e inscribirse en el Registro Mercantil, como es obligatorio para todas las emisiones de valores negociables agrupados en emisiones (art. 22.2 del C.Co. y art. 94.2 RRM). En la emisión de "PPR emitidas de forma directa" interviene una sociedad: la sociedad emisora, domiciliada en Espańa.

Dentro del epígrafe "otras preferentes" se incluyen cuatro emisiones reguladas en la D.A. segunda de la Ley 19/2003: 
a) Participaciones preferentes emitidas por entidades financieras sujetas a supervisión prudencial cuando no sean entidades de crédito

b) Instrumentos financieros de deuda del número 5 de la D.A. segunda de la Ley 19/2003 y emitidos por entidades financieras objeto de supervisión prudencial. Estas deudas pueden revestir la forma de obligaciones subordinadas, participativas y similares, pudiendo disfrutar así de una computabilidad de Tier two.

c) Participaciones preferentes e instrumentos de deuda del número 6 de la D.A. Segunda de la Ley 19/2003 emitidas por cotizadas.

d) Otros instrumentos financieros participativos, distintos de los tres anteriores, pero con características financieras similares a las PPR.

2.- Las PPR nacen por el deseo de las empresas de acercarse a la posición ideal de confeccionar un título con las características económicas de fondos propios pero con la calificación fiscal de deuda.

La legislación espańola permite emitir acciones o participaciones sociales preferentes, rescatables y sin voto, con exactamente los mismos derechos económicos y jurídicos que las PPR. La única diferencia puede derivarse de su calificación jurídica, por esta razón, en este artículo se ha indagado sobre si las PPR tienen o no la característica jurídica de acciones o participaciones sociales. Las PPR emitidas de forma directa y las "otras preferentes" no son acciones; las PPR emitidas de forma indirecta sí son acciones pero de otra legislación; las acciones o participaciones sociales preferentes, rescatables y sin voto son acciones reguladas en Espańa. Este dato es importante pero no determinante. El elemento determinante es que la legislación española confiere a las acciones y participaciones sociales un trato fiscal discriminatorio. Por tanto, es fácil predecir que, mientras que existan más incentivos fiscales sobre las PPR, las empresas españolas seguirán sin emitir, de forma masiva, las clases de acciones o participaciones sociales emitidas en Espańa; por el contrario sí emitirán acciones extranjeras (PPR emitidas de forma indirecta en España, pero acciones en las legislaciones extranjeras) o emitirán PPR emitidas de forma directa en España.

Para la economía española en general sería mejor que esas emisiones se realizaran en nuestro territorio porque la recaudación de los impuestos de esas emisiones se quedaría en las arcas de la Hacienda Pública española. También tiene aspectos positivos la emisión de PPR en Espańa para los emisores porque se ahorrarían la existencia de una sociedad filial extranjera. La decisión de realizar las emisiones en Espańa o en un paraíso fiscal depende fundamentalmente de que el ahorro por no tener que emitir una sociedad filial extranjera sea superior al ahorro de impuestos por emitir en un paraíso fiscal. Por todo ello, para atraer las emisiones de PPR a Es- 
paña, es necesario disminuir la carga fiscal para el emisor, de forma que disminuyan los incentivos para crear una filial extranjera.

3.- Hasta el momento, la legislación de los intermediarios financieros ha beneficiado claramente la emisión de PPR, perjudicando ostensiblemente la elección del emisor por las clases de acciones.

A parte de las motivaciones fiscales, la razón fundamental de que los intermediarios financieros hayan emitido PPR, y no acciones preferentes, rescatables o sin voto legisladas en España, es que si las PPR cumplen una serie de condiciones (no acumulativas, con opción de rescate solo del emisor y previa aprobación del supervisor), se computan como Tier 1. Con la emisión de PPR se ha estado consiguiendo la obtención de aspectos retributivos ventajosos, pero cumpliendo los requerimientos legales de recursos propios.

Todo esto cambiará con Basilea III. Las PPR emitidas por los bancos y cajas espańolas, que actualmente forman parte del Tier 1 (capital, reservas y preferentes), dejarán de contar en el Tier 1, por lo que no interesará a los intermediarios financieros mantenerlas. Para que las preferentes puedan formar parte del Tier 1, se les exigirá que puedan absorber pérdidas, es decir, que el intermediario financiero pueda amortizarlas por menos del nominal si tiene problemas económicos, situación que no ocurre con ninguna emisión de las que actualmente circulan en el mercado. Así pues, lo lógico es pensar que las actuales PPR serán amortizadas antes de 2023. Por supuesto nadie obligará a los bancos y cajas a amortizar sus emisiones, pero una vez perdida su utilidad para incrementar su nivel de solvencia del intermediario financiero, solo queda el criterio económico. Al no interesarles económicamente mantener vivas estas emisiones, es posible que los emisores potenciales reorienten sus emisiones hacia cualquier otro híbrido financiero. 


\section{BIBLIOGRAFÍA}

- Alonso Conzález P. (2001). "Las participaciones preferentes en Espańa”, Actualidad Financiera, julio, no 7, 19-31.

- Asociación Española de Contabilidad y Administración de EMpresas (AECA) (2008). Calificación contable de instrumentos financieros: Distinción pasivo patrimonio neto, documentos 25 Principios contables, septiembre. Madrid: AECA.

- Bajas, Mukesh; Mazumdar, Sumon, C; Sarin, Atulya (2002) "The cost of issuing preferred stock", Journal of Financial Research, 25 (4), pp. 577-592.

- Bankia: "Valores: renta fija", Página web corporativa, http://www. bankia.es/bankia/Home/cruce/0,0,199_997818*3839,00.html, consulta realizada el 10/6/2010.

- Cary; Collins; Wansley (2003). "The impact of trust preferred issuance of bank default risk and cash-flow: evidence from the debt and equity markets" The Financial Review, may, vol. 38, n 2, pp. 235 y ss.

- Cazorla Prieto, L. M.; Blázquez Lidoy, E. (2007). "Implicaciones fiscales de las participaciones preferentes", Estudios en homenaje al profesor Pérez de Ayala. Madrid: Editorial Dikynson.

- Chamorro Domínguez, M.C. (2009). "Las acciones rescatables como instrumento de financiación de planes de opciones sobre acciones", Actualidad jurídica, no 27, pp. 42-44.

- Chamorro Domínguez, M.C. (2007). Las acciones rescatables de la sociedad anónima cotizada. Madrid: La Ley.

- Comisión Nacional del Mercado de Valores- CNMV (2008). Participaciones preferentes (PPR). Oficina de Atención al Inversor. Madrid: CNMV.

- Comisión Nacional del Mercado de Valores- CNMV (2002). Los productos de renta fija, CNMV.

- Comisión Nacional Del Mercado De Valores- CNMV (1999) Informe Anual sobre Mercados de Valores. Madrid: CNMV.

- Conllado Lantero, F. (2002) "La emisión de acciones preferentes por sociedades bancarias españolas", en Libro Homenaje al Profesor Fernando Sánchez Calero, vol. IV, Madrid: (n/d).

- Dirección General del Tesoro y Política Financiera (n/d) Cortes Generales Diario de Sesiones del Senado, http://www.senado.es/ legis8/publicaciones/html/textos/CS0344.html.

- El País (2010) Negocios, 13 de diciembre de 1998, http://www. elpais.es/, consulta realizada el 26 de mayo de 2010.

- Engel, E.; Erickson, M.; Maydew, E (1999) "Debt-equity hybrid securities", Journal of Accounting Research, no 2, pp. 249-274. 
- Expansión (2005). "Solbes bloquea la fuga de capitales hacia los grandes paraísos fiscales”, Diario Expansión, 31 de mayo de 2005, pág. 28.

- Fernández, D. (2009). "El jaleo de las preferentes", Dinero \& inversiones, 12 de abril de 2009.

- Fernández del Pozo, L. (2005). Las participaciones preferentes: un hibrido supletorio del capital social. Madrid: Thompson Civitas.

- Fernández del Pozo, L. (2005). "Derechos políticos en cabeza de no-socios. El caso de las participaciones preferentes", en AA.VV Derecho de Sociedades Anónimas cotizadas, vol. I, Revista de Derecho de Sociedades, Thompson-Aranzadi, pp. 571-615.

- Fernández del Pozo, L. (2005). "Gobierno corporativo e híbridos financieros. Derechos políticos en cabeza de no-socios. El caso de las participaciones preferentes", en AA.VV Derecho de Sociedades Anónimas cotizadas, vol. I, Revista de Derecho de Sociedades, Thompson-Aranzadi, pp. 571-615.

- Fondo Monetario Internacional (2002). Offshore Financial Centers. The Role of the IMF, 23 june 2002.

- Frischmann, P. J.; Kimmel, P.D.; Warfield, T.D. (1999). "Innovation in preferred stock: current developments and implications for Financial Reportings", Accounting Horizons, september, pp. 201-218.

- García de Enterría, J. (1999). "Las acciones rescatables", La Ley, no 4847, 26 de julio, 1999, p. 2.

- García Vega, M.A. (2009) "El riesgo de invertir en las 'preferentes', http://www.dossierempresarial.com/leernoticia.asp?id=3557.

- Khana, A; Mc Connel, J.J. (1998). "MIPS, QUIPS and TOPRS: old wine in new bottles", Journal of Applied Corporate Finance, $\mathrm{n}^{\circ} 1$, pp. 40-52.

- Klein, W.A.; Coffee, J.C.J. (2000). Business organization and finance, $7^{\text {a }}$ ed. New York: Westbury, p. 225.

- Hamilton, Robert W.(1996). The Law of Corporation. St. Paul, Minnesota: West Publishing Co.

- Harris, A. J. (2004). "Trust preferred securities still eligible capital treatment; new rules are a compromise", Banking law journal, vol. $121, \mathrm{n}^{\circ} 8,688-696$.

- Henn, H. G.; Alexander, J.R. (1986). Laws of Corporation. Saint Paul, Minnesota: West Publishing Co.

- Heskins, M. (1995). "Can the IRS maintain the debt-equity distinction in the face of structures notes?", en Harvard Journal of Legislation, 32, pp. 524 y ss.

- Howells, P.; Bain, K.(2002). The economics of money, banking and finance, $2^{\mathrm{a}} \mathrm{ed}$. N/d: Prentice Hall. 
- International Accounting Standard Board (IASB) (1998). International Accounting Standard no 39: Financial Instruments: Recognition and measurement, december, IASB, London.

- International Accounting Standard Board (IASB) (1995). International Accounting Standard $\mathrm{n}^{\circ}$ 32, Financial instruments: Disclosures and presentation, june, London, 1995.

- Lamandini, M. (2001). Struttura finanziaria e gobernó nelle societa di capital. Bologna: Il Mulino.

- Martín, C. (2003). "El Congreso amnistía las emisiones de bancos y cajas en paraísos fiscales", Diario El Pais, http://www.elpais.es/, 26 marzo 2003.

- Martínez, M. (2009). Lo que su banco no le dice al ofrecerle acciones preferentes. Expansión, 17 de mayo de 2009.

- Mourgues, N. (1996). Capitaux propres et quasi fonds propres. Paris : Économie.

- Nelken, I. (2000). Handbook of hybrid instruments: convertible bonds, preferred shares, ELKS, DECS and other mandatory convertible notes, N/d: John Wiley \& Sons.

- Pisano Massamormile, A. (2003). "Azioni ed altri strumenti finanziari partecipaviti”, Rivista delle Societá, pp. 1268-1315.

- Scherk, W. (2003). "Emisiones preferentes: a medio camino entre las acciones y las obligaciones", Bolsa de Madrid, marzo, 68-69.

- Schwartz, R.J.; Clifford W.S.J. (1993). Advanced Strategies in Financial Risk Management. New York: New York Institute of Finance.

- Sinkey, J.F.J. (2003). "Bank capital structure, regulatory capital, and securities inonovations”, Journal of Money, Credit \& Banking, no 3, 301-335.

- Yanes Yanes, P. (2004). Las acciones rescatables en la sociedad cotizada. Cizur Menor (Navarra): Thomson-Aranzadi. 